\title{
THE
}

\section{Loop Current Eddy Formation and Baroclinic Instability}

\author{
Kathleen A. Donohue \\ University of Rhode Island, kdonohue@uri.edu \\ D. R. Watts \\ University of Rhode Island \\ P. Hamilton \\ R. Leben \\ M. Kennelly \\ University of Rhode Island
}

Follow this and additional works at: https://digitalcommons.uri.edu/gsofacpubs

The University of Rhode Island Faculty have made this article openly available.

Please let us know how Open Access to this research benefits you.

This is a pre-publication author manuscript of the final, published article.

Terms of Use

This article is made available under the terms and conditions applicable towards Open Access Policy Articles, as set forth in our Terms of Use.

\section{Citation/Publisher Attribution}

Donohue, K., Watts, D.R., Hamilton, P., Leben, R., \& Kennelly, M. (2016). Loop Current Eddy Formation and Baroclinic Instability. Dynamics of Atmospheres and Oceans, 76(2), 195-216.

Available at: http://dx.doi.org/10.1016/j.dynatmoce.2016.01.004

This Article is brought to you for free and open access by the Graduate School of Oceanography at DigitalCommons@URI. It has been accepted for inclusion in Graduate School of Oceanography Faculty Publications by an authorized administrator of DigitalCommons@URI. For more information, please contact digitalcommons-group@uri.edu. 


\title{
Loop Current Eddy Formation and Baroclinic Instability
}

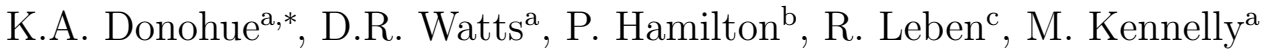 \\ ${ }^{a}$ Graduate School of Oceanography, University of Rhode Island, Narragansett, Rhode \\ Island USA \\ ${ }^{b}$ Leidos Inc. Raleigh, North Carolina, USA. \\ ${ }^{c}$ Department of Aerospace Engineering Sciences, University of Colorado Boulder, \\ Boulder, Colorado, USA.
}

\section{Abstract}

The formation of three Loop Current Eddies, Ekman, Franklin, and Hadal, during the period April 2009 through November 2011 was observed by an array of moored current meters and bottom mounted pressure equipped inverted echo sounders. The array design, areal extent nominally $89^{\circ} \mathrm{W}$ to $85^{\circ} \mathrm{W}, 25^{\circ} \mathrm{N}$ to $27^{\circ} \mathrm{N}$ with $30-50 \mathrm{~km}$ mesoscale resolution, permits quantitative mapping of the regional circulation at all depths. During Loop Current Eddy detachment and formation events, a marked increase in deep eddy kinetic energy occurs coincident with the growth of a large-scale meander along the northern and eastern parts of the Loop Current. Deep eddies develop in a pattern where the deep fields were offset and leading upper meanders consistent with developing baroclinic instability. The interaction between the upper and deep fields is quantified by evaluating the mean eddy potential energy budget. Largest down-gradient heat fluxes are found along the eastern side

\footnotetext{
*Corresponding author

Email address: kdonohue@uri.edu (K.A. Donohue)
} 
of the Loop Current. Where strong, the horizontal down-gradient eddy heat flux (baroclinic conversion rate) nearly balances the vertical down-gradient eddy heat flux indicating that eddies extract available potential energy from the mean field and convert eddy potential energy to eddy kinetic energy. Keywords:

Highlights:

- Large Loop Current meanders develop prior to separation as deep eddy energy grows

- A train of upper-deep eddy interactions leads to each Loop Current Eddy separation

- Deep eddies develop in a pattern consistent with baroclinic instability

- Mean eddy potential energy budget is evaluated with observations

- Horizontal downgradient eddy flux drives eddy kinetic energy

\section{Introduction}

The Loop Current (LC) dominates the circulation in the Gulf of Mexico.

3 As part of the North Atlantic western boundary current system, it enters the ${ }_{4}$ Gulf through the Yucatan Channel and exits through the Straits of Florida.

5 While the shortest circuit within Gulf is a port-to-port mode along the north6 ern Cuban coast, the LC can penetrate the Gulf as far north as $28^{\circ} \mathrm{N}$ and as 7 far west as $93^{\circ} \mathrm{W}$, expanding in area by a factor of 4 from the port-to-port 
to the far western Gulf due to the formation of large anticyclonic rings known as Loop Current Eddies (LCE). On an irregular time interval a LCE pinches off from the LC and migrates westward in the Gulf, the time interval between separations can be as rapid as a few weeks or as long as 18 months (Vukovich and Maul, 1985; Sturges and Leben, 2000; Leben, 2005). The LCE separation process is not readily predictable, although an empirical linkage between retreat latitude and subsequent separation time has been found (Leben, 2005; Alvera-Azcárate et al., 2009). Complex and multi-scale circulation is associated with the LCE formation (Sturges and Leben, 2000). The separation cycle often exhibits a series of detachments and reattachments before the final separation (see, for example, the LCE Franklin formation discussed in Liu et al. (2011b)). Frontal eddies and meanders along the periphery of the LC are present during separation (Cochrane, 1972; Vukovich and Maul, 1985; Fratantoni et al., 1998; Zavala-Hidalgo et al., 2003). The LC's influence extends beyond the depth of its surface-intensified core. Through interaction with topography and LCE generation, the LC provides the primary forcing of deep circulation. It has been hypothesized that deep energy generated beneath the LC during LCE separation radiates away from its source to the Gulf's boundary either as linear waves or eddies (Hamilton, 2009). At the boundary, steep escarpments act to focus this deep energy into narrow swift boundary currents (Oey and Lee, 2002; Oey, 2008).

Although qualitative analysis of surface fields has led to a classification of separation modes based upon the juxtaposition of cyclonic eddies and LC position within the Gulf (Schmitz, 2005), to date no theoretical framework fully explains LCE formation. Pichevin and Nof (1997) and Nof and Pichevin 
(2001) show that in order to conserve momentum, an anticyclonic eddy forms as the northward flowing LC turns eastward and realistic numerical models have demonstrated this process (Chérubin et al., 2005; Chang and Oey, 2011). Numerical studies highlight the role of instability and LC-topographic interactions in LCE formation e.g. Hurlburt and Thompson (1980); Hurlburt (1986); Welsh and Inoue (2000); Oey (2008); Chérubin et al. (2006); Le Hénaff et al. (2012). Essential in these studies are the feedbacks between upper and deep circulation. Hurlburt (1986) and Oey (2008) suggested that the region north of Campeche Bank is an important area for generation of deep eddies. Large mean-to-eddy energy conversion rates appear along the western edge of the Loop Current as the current moves off the relatively shallow western slope of the Yucatan Channel into the deep topography of the Gulf. Eddies propagate upstream along the Loop Current, grow in strength off the west Florida Slope and participate in the LC's necking-down that precedes LCE separation (Oey, 2008). In the Gulf of Mexico literature "necking-down" is often used to describe the spatial configuration where one or more adjacent LC cyclones appear to pinch together the sides of an extended LC below a developing LCE giving the LC a neck-like feature, e.g. Schmitz (2005). Chérubin et al. (2005) showed that a baroclinically unstable vortex generates a vigorous deep eddy field whose interaction with the LC becomes increasingly complex when realistic Gulf topography is included. More recently, the simulations in Le Hénaff et al. (2012) show that as frontal cyclones propagate over the Mississippi Fan, a coupled upper-deep cyclone pair develops that ultimately facilitates the LCE shedding process. Several studies have suggested linkage between the passage of cyclonic eddies from the Caribbean 
through Yucatan Channel to subsequent LCE separation (Oey et al., 2003; Oey, 2004; Athié et al., 2012; Huang et al., 2013).

To address the need for full-water column observations during the full eddy shedding cycle in order to improve the dynamical understanding of how the LC interacts with and drives deep circulation, an array of twenty-five inverted echo sounders with pressure gauges (PIES), nine full-depth moorings and seven near-bottom moorings was deployed April 2009 and recovered in October-November 2011 as part of the Dynamics of the Loop Current in US Waters Study (Figure 1). Three LCEs formed during the 30-month deployment, Ekman, Franklin, and Hadal (Figure 2). The array spanned $89^{\circ} \mathrm{W}$ to $85^{\circ} \mathrm{W}, 25^{\circ} \mathrm{N}$ to $27^{\circ} \mathrm{N}$ with $30-50 \mathrm{~km}$ mesoscale resolution. This permits quantitative mapping of the regional circulation during the LCE separation events. Hamilton et al. (2015), this volume, provides a review of the experiment and Hamilton et al. (2014) gives a detailed description of the field operations and data processing.

We note that the Deepwater Horizon oil-spill event occurred in springsummer 2010 and coincided in time with Eddy Franklin's formation. (The Deepwater Horizon platform, $88.39^{\circ} \mathrm{N}, 28.74^{\circ} \mathrm{N}$, was located well to the north, $230 \mathrm{~km}$ from the northwesternmost edge of the array discussed in this work.) Considerable efforts were made during that time period to rapidly acquire and analyze oceanographic observations as well to focus and improve modeling studies. A thorough review of the subsequent literature is beyond the scope of this study, as a starting point, the reader is referred to the dedicated monograph, 'Monitoring and Modeling the Deepwater Horizon Oil Spill: A Record-Breaking Enterprise' (Liu et al., 2011a) which provides a thorough 
synopsis of those initial efforts and in particular the studies of Walker et al. (2011); Liu et al. (2011b); Shay et al. (2011); Hamilton et al. (2011) which focus on large and meso-scale circulation in spring-summer 2010.

This paper focuses upon the coupling between the upper and deep circulation during LCE formation. We describe the data set in Section 2, statistics related to the deep circulation are provided in Section 3; case studies of upper-deep coupling for the three eddy events are shown Section 4; the mean potential energy budget is diagnosed in Section 5, and the paper concludes with a discussion and conclusion in Sections 6 and 7.

\section{Data}

The observational array consists of nine tall moorings, seven short moorings and twenty-five PIES. The suite of instrumentation on the tall moorings includes an upward-looking $75-\mathrm{kHz}$ acoustic Doppler current profiler at $450 \mathrm{~m}$ depth and point current meters at 600, 900, 1300, $2000 \mathrm{~m}$ depth and $100 \mathrm{~m}$ above the bottom as well as temperature recorders placed at 75, 150, $250,350,525,750,1100,1500 \mathrm{~m}$ depth. Short moorings have one current meter positioned $100 \mathrm{~m}$ above the bottom. The PIES, moored at the sea floor, emits $12 \mathrm{kHz}$ sound pulses and measures the round trip acoustic travel times, $\tau$, of these acoustic pulses from sea floor to sea surface, and a pressure gauge contained within the instrument's housing measures bottom pressure. Sampling frequency from the multiple sensors varies from minutes to hours. Here we utilize time series that have been 72-hour low pass filtered with a fourth order Butterworth filter and subsampled at 12-hour intervals. The Loop Current Study had excellent data return: 100\% PIES and 94\% tall 
and short moorings. A detailed description of instrumentation and standard processing is provided in Hamilton et al. (2014).

Using empirically-derived look-up tables between $\tau$ and historical hydrography (a so-called GEM field, Meinen and Watts (2000)), vertical profiles of temperature, salinity, and density are estimated. Hamilton et al. (2014) and Donohue et al. (2015) discuss specific treatment of this methodology to the Gulf. Application of objective analysis yields 4-dimensional maps of temperature, salinity, density, and geostrophic streamfunction at 12-hour intervals. An example of the mapped products for June 24, 2009 is shown in Figure 3. The vector sums of mapped baroclinic velocity profiles (geostrophic velocities referenced to zero at 3000 dbar, subscript $b c b$ ) plus deep reference velocities (subscript ref) give the estimated absolute geostrophic velocities throughout the water column. Absolute sea surface heights, SSH, are also determined. First, 3000-dbar pressures are converted to their height equivalent (leveled pressure anomaly divided by gravity and density). We term this component the reference level sea surface height $\left(\mathrm{SSH}_{r e f}\right)$. Second, surface geopotentials referenced to 3000 dbar are converted to their height equivalent (geopotential divided by gravity). Geopotential height is estimated from the GEM fields combined with measured $\tau$. We term this component the baroclinic SSH referenced to the bottom $\left(\mathrm{SSH}_{b c b}\right)$. The $b c b$ and the ref contributions to sea surface height are combined to yield absolute sea surface height. Equations 1-3 summarize the SSH calculation,

$$
\begin{aligned}
\mathrm{SSH}_{r e f} & =\frac{p_{r e f}}{\rho_{b} g} \\
\mathrm{SSH}_{b c b} & =\frac{\phi_{b c b}}{g},
\end{aligned}
$$




$$
\mathrm{SSH}_{a b s}=\mathrm{SSH}_{r e f}+\mathrm{SSH}_{b c b},
$$

where $g$ is gravity, $\rho_{b}$ is mean bottom density, $\phi_{b c b}$ is geopotential referenced to $3000 \mathrm{dbar}$, and $p_{\text {ref }}$ are the 3000-dbar pressures. This decomposition of SSH has been successfully applied with PIES in other strong western boundary current systems such as the Agulhas (Baker-Yeboah et al., 2009), the Kuroshio Extension (Park et al., 2012), and the Antarctic Circumpolar Current (Behnisch et al., 2013).

Extensive intercomparison between mapped fields and point measurements indicates that the PIES methodology works well in this region. Details and comparison figures are provided in Hamilton et al. (2014) and Donohue et al. (2015), this volume. Briefly, temperature comparisons, for the nine tall moorings at 9 depth levels reveal correlation coefficients greater than 0.92 at all depths, and greater than 0.975 at all sites for depths between 250 and $750 \mathrm{~m}$, indicating that the PIES capture more than $95 \%$ of variance. Rms differences are near $0.6^{\circ} \mathrm{C}$ at $250 \mathrm{~m}$ depth and decrease to $0.23^{\circ} \mathrm{C}$ at $900 \mathrm{~m}$ depth. PIES-mapped currents were compared to mooring currents at six nominal depths. Correlation coefficients are above 0.89 , especially within the thermocline. Rms differences are less than $10 \mathrm{~cm} \mathrm{~s}^{-1}$ everywhere and decrease to less than $5 \mathrm{~cm} \mathrm{~s}^{-1}$ below $600 \mathrm{~m}$ depth. PIES SSH and along-track Jason-2 altimeter SSH also compare well, correlation coefficients are above 0.95. Comparisons with along-track Jason-2 altimeter SSH anomaly confirm an estimated PIES SSH error of $5.7 \mathrm{~cm}$.

To place the array in the larger regional context, we take advantage of mapped satellite altimeter data. LCE separation times and LC area as well as the mapped fields are determined from the Colorado Center for Atmo- 
spheric Research (CCAR) Gulf of Mexico (GOM) objectively mapped historical mesoscale altimeter data reanalysis. These products use the quicklook mesoscale processing system (Leben et al., 2002) based on RADS 3.0 archive. Gridding uses a multigrid Cressman objective analysis of all available altimeter data. The satellite altimeter data used to produce the historical reanalysis during the observational program include Jason-1, Envisat, and OSTM/Jason-2. A detailed description of the processing of the GOM SSH dataset can be found in Hamilton et al. (2014). Detachment of LCEs from the LC is identified by the breaking of the $17-\mathrm{cm}$ SSH contour in the CCAR GOM historical SSH data product. In this product, the 17-cm SSH contour closely tracks the core of the LC that enters through the Yucatan Channel and exits through the Florida Straits (Leben, 2005). Dukhovskoy et al. (2015) provides an evaluation of the tracking technique.

\section{Deep statistics}

In contrast to the broad anticyclonic mean flow observed in the upper ocean (Figure 4a), the mean deep circulation exhibits more structure (Figure $4 \mathrm{~b})$. Along the western side of the array, a deep mean anticyclonic gyre with $\sim 200 \mathrm{~km}$ lateral extent is centered near $26.3^{\circ} \mathrm{N} 87.3^{\circ} \mathrm{W}$ with mean speeds near $6 \mathrm{~cm} \mathrm{~s}^{-1}$. In the east, there is a deep mean cyclonic gyre positioned near $26.2^{\circ} \mathrm{N} 85.7^{\circ} \mathrm{W}$ with speeds near $3 \mathrm{~cm} \mathrm{~s}^{-1}$. Along the southern boundary of the array, mean deep flow is to the north and west. Standard deviation ellipses are mainly isotropic except at the mooring closest to the west Florida Shelf where the ellipse is elongated and parallel to the slope. Elevated timemean eddy kinetic energy (EKE) is found beneath the mean position of the 
LC. This swath of high EKE can be traced from the Mississippi Fan, where it is offset slightly to the north of the mean LC position, across the array to the southeast, where the EKE maximum lies slightly west of the mean LC. Array-averaged EKE shows the influence of the LC (Figure 4, panels c,d ). Enhanced EKE occurs during LCE shedding events. During Ekman, Franklin, and Hadal, peak EKE occurs at or near the first eddy detachment. An additional EKE peak occurs in June 2011, during this time, the LC necks down but does not form an eddy. During LC eddy detachment and formation events, a marked increase in deep eddy kinetic energy occurs (Figures 4d) coincident with the development of a large-scale meander along the northern and eastern parts of the LC (Figure 2).

Mesoscale variance distribution as a function of frequency also differs between the upper and deep ocean. The discussion will treat variance whereas Figure 5 displays standard deviation. Note the range choices for the frequency bands shown in Figure 5 are based upon spectral peaks shown in Figure 6. Upper-ocean variance is dominated by the low-frequency lateral movement of the LC in and out of the array during LC eddy shedding cycles, and only $14 \%$ of the variance is in periods shorter than 100 days (Donohue et al., 2015). There is proportionally more deep variance in the highfrequency bands (Figure 5): $72 \%$ of the deep variance is in periods shorter than 100 days. Within the 100- to 3-day mesoscale band, deep variance is distributed as follows: $57 \%$ within 100 to 40 day, 30\% within 40 to 20 day, $13 \%$ within 20 to 3 day. Similar to the upper ocean, the spatial structure of the deep variance changes as a function of frequency band (Figure 5). Within the highest frequency band, 20 to 3 days, elevated values occur along 
the base of the Mississippi Fan in the northwest portion of the array. As frequency decreases, this ridge of high variance shifts to the southeast within the array. In the lowest frequency band, 100 to 40 days, the spatial pattern resembles the time-mean EKE (Figure 4).

A signature of growing baroclinic instability events is a vertical phase tilt: along the direction of propagation, with deep fields leading upper fields. Consequently, at a fixed location, deep leads upper in time also. To investigate vertical coupling, the coherences and phases between upper and deep streamfunctions $\left(\mathrm{SSH}_{b c b}\right.$ and $\mathrm{SSH}_{r e f}$, respectively) are estimated using the averaged periodogram method of Welch (1967) (256-day length segment with $50 \%$ overlap). Upper and deep streamfunctions are coherent over large portions of the array for frequencies between $1 / 64 \mathrm{~d}^{-1}$ and $1 / 32 \mathrm{~d}^{-1}$. Figure 7 shows the spatial pattern of coherence and phase for three frequencies within this band. A tongue of high coherence extends from the northeast trending south-southwest toward the central portion of the array where the three LCE's separated. Two additional peaks occur, one near the base of the Mississippi Fan and another in the southeastern corner. Where statistically coherent, the phase offset is such that the deep leads the upper. Phase estimates range between 60 and 150 degrees. Frequencies outside the band $1 / 64 \mathrm{~d}^{-1}$ and $1 / 32 \mathrm{~d}^{-1}$ do not show statistically significant coherence between upper and deep.

\section{Case Studies}

The preceding spectral approach characterizes the overall mean statistics, yet each LC eddy shedding event is unique, e.g., location of final separation, 
number of brief detachments that precede the separation, location of the LC regarding bottom topography and what portion was mapped by the array (Figure 2). To illustrate the evolution of LC eddy-shedding events and the relationship between upper and deep, maps of upper and deep streamfunction are plotted at short time intervals (four-to-five days). In each case study, mapped baroclinic SSH referenced to the bottom $\left(\mathrm{SSH}_{b c b}\right.$, filled colored contours) is embedded within altimetric SSH that covers the broader region. The 17-cm contour denotes the location of the LC and LC-eddy fronts. Mapped $\mathrm{SSH}_{r e f}$ reveals the presence of deep cyclones (blue contours) and deep anticyclones (red contours). Two sets are provided for each shedding event: full frequency (3-day low-pass), and 100 to 40-day band pass fields (Figures 8 - 9 for Ekman, Figures 10 - 11 for Franklin and Figures 12 - 13 for Hadal). The following discussion focuses upon the 100 to 40 day band in which coherence between upper and deep is found to be high.

Eddy Ekman: 4 May to 4 October 2009. A long-wavelength meander develops along the northern edge of the LC in early July (Figure 8). Perturbations in the deep field begin to appear in early May and intensify in late July. The 4 July map depicts two deep eddies labeled as cyclone A and anticyclone B (Figure 9). These two deep eddies are positioned on this date such that the deep anticyclone B leads an upper high, and the deep cyclone A slightly leads an upper low. This classic pattern associated with baroclinic instability remains with varying vertical phase-tilt as the meander and deep eddies propagate together anticyclonically along the LC periphery from 4 July to 25 August. While the amplitude of deep cyclone A remains nearly constant during this interval, deep anticyclone B's strength modulates. Anticyclone 
B intensifies from 8 to 20 July, remains constant in strength until 28 July, then weakens over the next 10 days. A slight re-amplification occurs $25 \mathrm{Au}-$ gust. On 24 July (Figure 9), another deep cyclone labeled C, located on the Mississippi Fan, begins to develop. It is positioned slightly downstream of a developing upper trough. This trough and deep cyclone C jointly intensify 24 July through 21 August. During this interval, the trough deepens to nearly pinch off the neck of the LC, and the vertical phase tilt gets smaller as deep cyclone $\mathrm{C}$ becomes nearly vertically aligned under the trough. By 29 August, the phasing of deep leading upper no longer exists, Eddy Ekman is nearly separated, and deep cyclone $\mathrm{C}$ has weakened and subsequently propagates southwestward out of the array.

Eddy Franklin: 11 April to 13 September 2010. Similar to Eddy Ekman, during the formation of Eddy Franklin, the signature vertical phase tilts of baroclinic instability are present. This case study includes upper and deep events leading to an eddy detachment in early July 2010 and final separation in early August 2010 (Figure 10). Consider the large-scale LC meander that is developing in early May 2010. The 11 May map (Figure 11) shows two deep eddies, anticyclone A and cyclone B. They are positioned such that the deep anticyclone resides downstream of and leads the upper crest. The deep cyclone B resides upstream of that upper crest, and in subsequent days ( 5 June to 25 June) cyclone B intensifies as it leads a developing upper trough within the array. Anticyclone $\mathrm{C}$ comes into view 5 June with an upper crest following close behind it. During June, the B and C deep eddies and their slightly trailing upper meander trough and crest propagate downstream around the Loop. The trough and deep eddy B jointly intensify, and by early 
July (Figure 11) the LC neck pinches off into a short-lived detachment. The 30 June map shows three deep eddies; a deep cyclone, labeled D, appears near the Mississippi Fan. The northern limit of the array leaves the question open as to whether these deep eddies (A, B, C or D) initially propagate into the array from further north, or whether they originate upstream along the LC front. During July, deep eddies C and D and their slightly trailing upper meander crest and trough propagate downstream around the LC. For example, on 10 and 15 July 2010, the vertical phase tilt is evident, and the features jointly intensify. Eventually, the trough 'necks down' again, and eddy separation occurs in August. The recurrent structure observed in these map sequences is that as deep eddies propagate through the array they lead their upper counterpart and this leads to joint amplification. For example, from 5 June to 10 July (Figure 11), deep cyclone B leads an upper cyclone (trough); from 15 July to 4 August, deep anticyclone C leads an upper anticyclone. Finally, we note that during the Franklin event, the largest amplitude deep eddies occur during the early to mid-July detachment, prior to the final separation of a relatively small LC eddy in August.

Eddy Hadal: 9 March to 11 August 2011. Upper-deep coupling with the vertical phase tilt of baroclinic instability also characterizes the Hadal shedding cycle. Figure 12, shows that during Hadal, long-wavelength meanders develop along the eastern side of an extended LC. The eastern side of the LC runs through the middle of the array during much of this time, and the associated deep eddies are relatively well centered within the observational window. This case study will follow a sequence of four deep eddies, anticyclones A and C, and cyclones B and D (Figure 13). As seen in our Ekman and Franklin 
case studies, while these deep eddies translate along the LC, they lead their upper counterpart as they jointly develop and tend to constrict the neck. For example, on 13 April, deep anticyclone A sits just downstream of an upper crest (high $\mathrm{SSH}_{b c b}$ ), and during the subsequent 15 days the upper and deep highs jointly intensify. Shortly after that, on 3 May deep cyclone B leads an upper trough (low $\mathrm{SSH}_{b c b}$ ), and both intensify during the subsequent 20 days. Immediately following that, on 23 May, the deep anticyclone C leads an upper crest downstream, intensifying during the next 20-30 days to about 22 June. Deep-cyclone D follows this train of upper-deep coupling interactions. From 22 June to 17 July 2011 deep-cyclone D leads and jointly develops with an upper low $\mathrm{SSH}_{b c b}$ and trough, constricting the LC neck greatly. Shortly afterward Hadal separates. Limits to the growth phase of the upper and deep perturbations appear to occur when the deep eddy trajectory turns to the southwest, not following the downstream path of the upper jet. Subsequently, their vertical phase tilt becomes non-conducive to baroclinic instability, and they jointly decay. Deep-cyclone B decays after 28 May together with its upper-strong low. Analogously deep-anticyclone C decays after 22 June together with its upper strong high. Similar to the Franklin event, large amplitude deep eddies and joint intensification (mid-April through late June) occur prior to the final eddy separation (mid-August).

\section{Eddy Potential Energy}

The terms in the time-mean eddy potential-energy budget are evaluated so as to diagnose the role of eddies in the system. The results below will demonstrate that eddies extract potential energy from the mean field (stored 
in the sloping isopycnals of the LC) and ultimately convert that energy to eddy kinetic energy.

Following Cronin and Watts (1996) and Bishop et al. (2013), a quasigeostrophic framework (small Rossby number, $\beta$ plane) is assumed to be valid for our diagnostics. Temperature will be a proxy for density: $\rho=\rho_{o}(1-\alpha T)$, where $\alpha$ is an effective thermal expansion coefficient $\left(10^{-4}{ }^{\circ} \mathrm{C}^{-1}\right)$. Potential energy budget terms are evaluated near $400 \mathrm{~m}$ depth. This avoids the nearsurface depth of subtropical underwater where the role of salinity would have to be independently included when calculating density.

In a Boussinesq incompressible fluid, the time-mean temperature equation can be written as:

$$
\overline{\boldsymbol{u}} \cdot \nabla \bar{T}=-\bar{w} \theta_{z}-\nabla \cdot \overline{\boldsymbol{u}^{\prime} T^{\prime}}
$$

where $\boldsymbol{u}=(u, v)$ is geostrophic velocity, $T$ is temperature, $w$ is vertical velocity and $\theta_{z}$ is the regional background vertical temperature gradient. Overbars indicate a time mean and primes are the deviation from the mean. In the following discussion, $\boldsymbol{u}^{\prime} T^{\prime}$ is referred to as 'heat flux' since implicitly eddy temperature flux multiplied by density and specific heat at constant pressure $\left(\rho_{o} C_{p}\right)$ is a heat flux. Equation 4 states that mean horizontal advection is balanced by mean vertical advection and the divergence of horizontal eddy heat flux. Note that the dynamically important part of the eddy heat flux term is the divergent component of eddy heat flux.

Eddy heat flux can be decomposed into rotational and divergent components by Helmholtz's theorem. The rotational component recirculates heat whereas the divergent component provides the net lateral heat flux that trans- 
fers potential energy into eddies. It is a challenge, numerically and observationally to isolate these divergent eddy heat fluxes from the total eddy heat flux (see Griesel et al. (2009) for a recent discussion).

The approach will be to take advantage of the vector decomposition, shown in Figure 3 and expressed as the baroclinic velocity relative to the bottom plus a bottom reference velocity, $\boldsymbol{u}=\boldsymbol{u}_{b c b}+\boldsymbol{u}_{r e f}$. In strong advective systems, mean $\psi_{b c b}$ streamlines are very nearly parallel to mean temperature contours and therefore do not advect mean temperature. Figure 14 shows the nearly linear relationship between mean $\psi_{b c b}$ and mean $T$ at $400 \mathrm{~m}$ within our array. Therefore

$$
\boldsymbol{u}_{b c b}^{\prime} \cdot \nabla T^{\prime}=0
$$

The divergent component of the heat flux arises from the nearly depthuniform reference current, of which a component can cross the time-varying baroclinic LC front. The dynamically important divergent heat flux is entirely contained in $\boldsymbol{u}_{r e f}^{\prime} T^{\prime}$. Figure 15 shows the mean eddy heat fluxes for the three LC eddy-shedding events superimposed on temperature variance. Eddy heat flux is calculated three ways for this illustration, using the total eddy velocity $\left(\boldsymbol{u}^{\prime} T^{\prime}\right)$, baroclinic eddy velocity $\left(\boldsymbol{u}_{b c b}^{\prime} T^{\prime}\right)$, and reference eddy velocity $\left(\boldsymbol{u}_{r e f}^{\prime} T^{\prime}\right)$. For each eddy event, $\boldsymbol{u}^{\prime} T^{\prime}$ has the largest magnitudes. As expected from Marshall and Shutts (1981) $\boldsymbol{u}_{b c b}^{\prime} T^{\prime}$ circulates around temperature variance illustrating its rotational non-divergent nature. $\boldsymbol{u}_{r e f}^{\prime} T^{\prime}$ shows downgradient heat fluxes in all events with strongest fluxes along the eastern side of the LC where the strongest growth occurred.

The eddy potential energy budget in steady state is determined by multiplying the temperature equation by $g \alpha T^{\prime} / \theta_{z}$ and averaging, 


$$
0=-\overline{\boldsymbol{u}} \cdot \nabla \frac{g \alpha}{2 \theta_{z}} \overline{T^{\prime 2}}-\nabla \cdot \overline{\boldsymbol{u}^{\prime} \frac{g \alpha}{2 \theta_{z}} T^{\prime 2}}-\frac{g \alpha}{\theta_{z}} \overline{\boldsymbol{u}^{\prime} T^{\prime}} \cdot \nabla \bar{T}-g \alpha \overline{T^{\prime} w^{\prime}}
$$

373

375

where eddy potential energy is defined as

$$
E P E=\frac{g \alpha}{2 \theta_{z}} \overline{T^{\prime 2}}
$$

Dividing by $\alpha g / \theta_{z}$ and rearranging yields,

$$
\underbrace{\overline{\boldsymbol{u}} \cdot \nabla \frac{1}{2} \overline{T^{\prime 2}}}_{\mathrm{MAP}}+\underbrace{\nabla \cdot \overline{\boldsymbol{u}^{\prime} \frac{1}{2} T^{\prime 2}}}_{\mathrm{EAP}}+\underbrace{\theta_{z} \overline{T^{\prime} w^{\prime}}}_{\mathrm{PKC}}=\underbrace{-\overline{\boldsymbol{u}^{\prime} T^{\prime}} \cdot \nabla \bar{T}}_{\mathrm{BC}}
$$

Equation 8 states that the horizontal down-gradient eddy heat flux (BC) is balanced by the mean advection of eddy potential energy (MAP), eddy advection of eddy potential energy (EAP) and the vertical down-gradient heat flux (PKC). In baroclinic instability, the eddy conversion term (BC) of mean potential energy to eddy potential energy is balanced by the eddy conversion of eddy potential to eddy kinetic energy (PKC).

If we decompose our velocity field as described above into the baroclinicreferenced-to-the-bottom and reference components, we can rewrite the eddy energy budget:

$$
\begin{aligned}
\overline{\boldsymbol{u}}_{b c b} \cdot \nabla \frac{1}{2} \overline{T^{\prime 2}}+\overline{\boldsymbol{u}}_{r e f} & \cdot \nabla \frac{1}{2} \overline{T^{\prime 2}}+\nabla \cdot \overline{\boldsymbol{u}_{b c b}^{\prime} \frac{1}{2} T^{\prime 2}}+\nabla \cdot \overline{\boldsymbol{u}_{r e f}^{\prime} \frac{1}{2} T^{\prime 2}}+\theta_{z} \overline{T^{\prime} w^{\prime}} \\
& =-\overline{\boldsymbol{u}_{b c b}^{\prime} T^{\prime}} \cdot \nabla \bar{T}+-\overline{\boldsymbol{u}_{r e f}^{\prime} T^{\prime}} \cdot \nabla \bar{T}
\end{aligned}
$$

4 temperature contours (Figure 15), there is a relationship between mean temperature and velocity (Marshall and Shutts, 1981):

$$
f \overline{\boldsymbol{u}}_{b c b}=2 \gamma \hat{\mathbf{k}} \times \nabla \bar{T}
$$


387

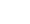

389

390

391

where $\gamma$ is an empirical constant,

$$
\gamma=\frac{1}{2} \frac{d \psi_{b c b}}{d \bar{T}}
$$

Cronin and Watts (1996) and Bishop et al. (2013) argue that instantaneous field

$$
f \boldsymbol{u}_{b c b}^{\prime}=2 \gamma \hat{\mathbf{k}} \times \nabla T^{\prime}
$$

also holds.

Equations 11 and 12 state that the baroclinic-referenced-to-the-bottom field is aligned vertically with the front ("equivalent barotropic"), which is a good approximation in our array (Figure 14). With this decomposition, the following relationships hold:

$$
\overline{\boldsymbol{u}_{b c b}} \cdot \nabla \frac{1}{2} \overline{T^{\prime 2}}=-\overline{\boldsymbol{u}_{b c b}^{\prime} T^{\prime}} \cdot \nabla \bar{T}
$$

and

$$
\nabla \cdot \overline{\boldsymbol{u}_{b c b}^{\prime} \frac{1}{2} T^{\prime 2}}=0
$$

Therefore, the mean eddy potential energy budget can be reduced to the following:

$$
\underbrace{\overline{\boldsymbol{u}_{r e f}} \cdot \nabla \frac{1}{2} \overline{T^{\prime 2}}}_{\text {MAP }_{r e f}}+\underbrace{\nabla \cdot \overline{\boldsymbol{u}_{r e f}^{\prime} \frac{1}{2} T^{\prime 2}}}_{\mathrm{EAP}_{r e f}}+\underbrace{\theta_{z} \overline{T^{\prime} w^{\prime}}}_{\mathrm{PKC}}=\underbrace{-\overline{\boldsymbol{u}_{r e f}^{\prime} T^{\prime}} \cdot \nabla \bar{T}}_{\mathrm{BC}_{r e f}}
$$

Hereafter the subscript ref will be dropped from Equation 15.

To calculate these terms, one needs to determine vertical velocity $w$ and mean $\theta_{z} \cdot \theta_{z}$ is determined by the mean stratification within the array and at $400 \mathrm{~m}$ depth has a value of $0.023{ }^{\circ} \mathrm{C} \mathrm{m}^{-1}$. Following Lindstrom and Watts 
(1994) and Howden (2000), vertical velocity is estimated near the base of the thermocline from the depth of the $6^{\circ}$ isotherm $\left(Z_{6}\right)$

$$
w=\frac{\partial Z_{6}}{\partial t}+\mathbf{u} \cdot \nabla Z_{6} .
$$

$Z_{6}$ is negative and becomes increasingly negative with depth.

Figures 16 through 21 in the following LCE-specific discussions show the results of calculating the terms in the mean eddy potential energy budget (Equation 15). The maps summarize the energy conversion rates over the time interval of each respective case study. It is beyond the scope of this work to try to close the energy budget. Rather the aim is to illustrate major process of energy conversion.

Eddy Ekman. The BC term closely balances the sum of the PKC, EAP and MAP terms (Figure 16). The BC term is positive (indicating down-gradient fluxes) along the northwestern corner near the Mississippi Fan and along the eastern side of the LC. Overall, the pattern in the PKC term corresponds well to the $\mathrm{BC}$ term, although their respective maxima and minima are slightly displaced. Time series of the $\mathrm{BC}^{\prime}$ and $\mathrm{PKC}^{\prime}$ terms in three regions where both terms are strong and positive are shown in Figure 17. Here $\mathrm{BC}^{\prime}$ is defined as $-\boldsymbol{u}_{r e f}^{\prime} T^{\prime} \cdot \nabla \bar{T}$ and $\mathrm{PKC}^{\prime}$ is defined as $\theta_{z} T^{\prime} w^{\prime}$. Time series track each other well and are positively correlated with one another, with correlation coefficients (r) ranging from 0.51 to 0.74 . The peaks in the time series can be traced back to dates when the deep eddies and upper $\mathrm{SSH}_{b c b}$ 100-to-40 day band passed fields jointly intensify (Figure 9). For the three time series shown here, located at the correspondingly color-coded stars on the map at the top of the figure, the peaks are associated with times when deep cyclone A 
intensifies as it propagates along the LC periphery: near the Mississippi Fan (magenta star in Figure 17) in mid-July, when deep anticyclone B intensifies at the northeast corner (blue star) in late July and when deep cyclone C intensifies in the southeast corner (cyan star) in early August.

Eddy Franklin. Similar to Ekman, during the Franklin event, the BC term closely balances the sum of the PKC, EAP and MAP terms (Figure 18). The $\mathrm{BC}$ term is positive (indicating down-gradient fluxes) near the base of the Mississippi Fan, along the eastern side of the LC as well as in the central portion of the array. Overall, the pattern in the PKC term corresponds well to the BC term, although the maxima and minima are again slightly displaced from one another. Additionally, the range of PKC values is larger than the $\mathrm{BC}$ range, particularly in the central array. Time series of the $\mathrm{BC}^{\prime}$ and $\mathrm{PKC}^{\prime}$ terms in three regions where both terms are strong and positive are shown in Figure 19. Note the vertical scale extends to higher rates than for the other two eddy separation case studies discussed here. Time series track each other well and are positively correlated with one another, with correlation coefficients $(\mathrm{r})$ ranging from 0.49 to 0.67. Positive $\mathrm{BC}$ and $\mathrm{PKC}$ peaks along the eastern side of the LC coincide with the propagation and development of several deep eddies. In the southeast (magenta star in Figure 19), peaks are due to the intensification of deep anticyclone A (Figure 11) in early May. Along the northeast (blue star in Figure 19) the peak is due to the intensification of deep cyclone B. In the central array (cyan star), the late-June $\mathrm{BC}$ and $\mathrm{PKC}$ peaks occur when deep anticyclone $\mathrm{C}$ intensifies.

Eddy Hadal. Just as for the Ekman and Franklin case studies, the BC term nearly balances the sum of the PKC, EAP and MAP terms (Figure 20). The 
BC term has a maximum just downstream of the Mississippi Fan near $26.2^{\circ} \mathrm{N}$, $86.2^{\circ} \mathrm{W}$. The PKC term is also high here, indicating that eddies gain potential energy from the mean LC and convert that energy to eddy kinetic energy. An additional maximum occurs in the PKC field, near $26.2^{\circ} \mathrm{N}, 87.5^{\circ} \mathrm{W}$, and here the balance is mainly between PKC and EAP. Figure 21 shows the time series of $\mathrm{BC}^{\prime}$ and $\mathrm{PKC}^{\prime}$ centered on a location where both terms sum to a strong positive peak. Again, the time series track each other well; the correlation coefficient is 0.86 . The two large peaks in the time series, late April and mid-May, coincide with the intensification of deep cyclone B and deep anticyclone C, respectively (Figure 13).

\section{Discussion}

These observations, resolving the full-water column mesoscale circulation, provide a new perspective on LCE detachment and separation. The 'necking down' of the LC is achieved through the amplification of the meander trough that extends across the LC. It is a full water-column process. During the LCE detachment and formation events, a marked increase in deep eddy kinetic energy occurs coincident with the growth of a large-scale meander along the northern and eastern parts of the LC. The trough deepens through a train of upper-deep eddy interactions that precede each separation. Strongest upperdeep interaction and the most energetic deep eddies can occur well in advance of the final eddy separation. Joint intensification is intermittent, lasting only tens of days while the vertical phase tilt is optimal for baroclinic growth. Topography allows the deep eddies to propagate across the neck between the base of the Mississippi Fan and the Campeche Bank to effectuate LCE 
detachment and separation.

A preferred time-scale for upper-deep coupling emerges. Upper and deep stream function are coherent within the frequency band between 100 and $40 \mathrm{~d}$, the spatial offset is one where, in the direction of propagation, deep leads upper. Donohue et al. (2015) and Hamilton et al. (2015), this issue, show that these fluctuations cannot be traced back to Yucatan Channel. This contrasts the historical view that it is the downstream growth of LC peripheral frontal eddies that leads to LCE formation. Due to the limited spatial domain of the array, we cannot identify the trigger mechanism. In other words, we cannot unambiguously distinguish between locally generated deep eddies and external deep eddies that may enter and intensify when they encounter favorable phasing with the upper thermocline waters. Peripheral eddies may yet play an important role in LCE formation. The modeling study of Le Hénaff et al. (2012) suggests that as upper layer frontal cyclones propagate over the Mississippi Fan, a deep cyclone is generated. In their simulation, the upper-deep pair is shown to propagate across the LC and facilitate LCE formation. Recent modeling efforts, (Chérubin et al., 2006; Oey, 2008) explore how the position of the LC relative to topography plays a role in the stability of the current, with particular focus on circulation near Campeche Bank and the western side of the LC. Results from this study instead highlight the importance of the northeast corner of the LC where rapid growth of LC meanders and generation of strong deep EKE occur.

The energetics for the three shedding events share the following characteristics. First, the magnitude of eddy advection of eddy potential energy, EAP, a triple-correlation term which has often been assumed small, must 
in fact be included in the budget, because it is of the same order as the baroclinic conversion (BC) and vertical down-gradient heat flux (PKC). The mean advection of eddy potential energy (MAP) by the ref field is small compared to the other four terms. The spatial pattern and magnitude of the combined PKC+EAP+MAP terms are very similar to the BC term. Second, at any particular location, the time series that contribute to the terms in the eddy energy budget are episodic in the LC, often with only a few events dominating the mean. Conversion of available potential energy to eddy kinetic energy occurs primarily along the eastern edge of the LC.

\section{Conclusion}

Deep eddies that occur during and near Loop Current Eddy detachment gain their high-energy levels in a pattern consistent with developing baroclinic instability. The periodicities associated with these are 100 to 40-days. Coherence estimates and case studies reveal that the deep streamfunction perturbations lead corresponding perturbations in the upper streamfunction, as they jointly intensify during a train of 3-4 cyclone/anticyclone pairs. This baroclinic instability is intrinsically a whole-water-column process, and the interaction between the upper and lower water column is quantified by evaluating the mean-eddy potential-energy budget. The baroclinic energy conversion term, represented by down-gradient eddy heat fluxes, is found to be largest along the eastern side of the LC. In these peak conversion regions there is a near balance between horizontal down-gradient eddy heat fluxes (baroclinic conversion rate) and vertical down-gradient eddy heat fluxes, indicating that eddies extract available potential energy from the mean baroclinic 
field and further convert that eddy potential energy to eddy kinetic energy.

\section{Acknowledgments}

The principal authors were supported by the Bureau of Ocean Energy Management (BOEM) through contract M08PC20043 with Leidos, Inc. (formerly Science Applications International Corporation, SAIC). The authors wish to thank Alexis Lugo-Fernandez, the contracting officer's representative for his enthusiastic support. The successful deployment and recovery of the array was due to the instrument development and careful preparation and planning by James Singer, Paul Blankinship, Erran Sousa, Stuart Bishop, Brian Roderick, Gary Savoie and Cathy Cippolla. R. Leben acknowledges support from BOEM contracts M08PC20043 and M10PC00112 to Leidos Corporation, and NASA Ocean Surface Topography Mission Science Team Grants NNX08AR60G and NNX13AH05G.

Alvera-Azcárate, A., Barth, A., Weisberg, R. H., 2009. The surface circulation of the Caribbean Sea and the Gulf of Mexico as inferred from satellite altimetry. J. Phys. Oceanogr. 39 (3), 640-657.

Athié, G., Candela, J., Ochoa, J., Sheinbaum, J., 2012. Impact of Caribbean cyclones on the detachment of Loop Current anticyclones. J. Geophys. Res. 117 (C3), C03018.

Baker-Yeboah, S., Watts, D. R., Byrne, D. A., 2009. Measurements of sea surface height variability in the eastern South Atlantic from pressure-sensor equipped inverted echo sounders: baroclinic and barotropic components. J. Atmos. Oceanic Technol. 26 (12), 2593-2609. 
Behnisch, M., Macrander, A., Boebel, O., Wolff, J.-O., Schörter, J., 2013. Barotropic and deep-referenced baroclinic ssh variability derived from pressure inverted echo sounders (pies) south of africa. J. Geophys. Res. 118 (6), $3046-3058$.

URL http://dx.doi.org/10.1002/jgrc. 20195

Bishop, S. P., Watts, D. R., Donohue, K. A., 2013. Divergent eddy heat fluxes in the Kuroshio Extension at $144^{\circ}-148^{\circ}$ E. Part I: Mean structure. J. Phys. Oceanogr. 43 (8), 1533-1550.

Chang, Y.-L., Oey, L.-Y., 2011. Loop Current Cycle: coupled response of the Loop Current with deep flows. J. Phys. Oceanogr. 41 (3), 458-471.

Chérubin, L. M., Morel, Y., Chassignet, E. P., 2006. Loop Current ring shedding: The formation of cyclones and the effect of topography. J. Phys. Oceanogr. 36, 569-591.

Chérubin, L. M., Sturges, W., Chassignet, E. P., 2005. Deep flow variability in the vicinity of the Yucatan Straits from a high-resolution numerical simulation. J. Geophys. Res. 110 (C4), C04009.

Cochrane, J. D., 1972. Separation of an anticyclone and subsequent developments in the Loop Current (1969). Contributions on the Physical Oceanography of the Gulf of Mexico 2, 91-106.

Cronin, M., Watts, D. R., 1996. Eddy-mean flow interaction in the Gulf Stream at 68W. Part I: Eddy energetics. J. Phys. Oceanogr. 26, 21072131. 
Donohue, K., Watts, D., Hamilton, P., Kennelly, M., Lugo-Fernández, A., 2015. Meanders along the Loop Current Path. Dynamics of Atmosphere and Ocean. submitted to, this issue.

Dukhovskoy, D. S., Leben, R. R., Chassignet, E. P., Hall, C. A., Morey, S. L., Nedbor-Gross, R., 2015. Characterization of the uncertainty of Loop Current metrics using a multidecadal numerical simulation and altimeter observations. Deep Sea Research Part I: Oceanographic Research Papers 100, 140-158.

Fratantoni, P. S., Lee, T. N., Podesta, G. P., Muller-Karger, F., 1998. The influence of Loop Current perturbations on the formation and evolution of Tortugas eddies in the southern Straits of Florida. J. Geophys. Res. 103, 24759-24779.

Griesel, A., Gille, S. T., Sprintall, J., McClean, J. L., Maltrud, M. E., 2009. Assessing eddy heat flux and its parameterization: A wavenumber perspective from a $1 / 10^{\circ}$ ocean simulation. Ocean Modelling 29 (4), 248 260.

Hamilton, P., 2009. Topographic Rossby waves in the Gulf of Mexico. Prog. Ocean. 82, 1-31.

Hamilton, P., Donohue, K., Leben, R. R., Lugo-Fernández, A., Green, R., 2011. Loop Current Observations during Spring and Summer of 2010: Description and Historical Perspective. In: Y. Liu, A. MacFadyen, Z.-G. J., Weisberg, R. (Eds.), Monitoring and modeling the Deepwater Horizon oil 
spill: a record-breaking enterprise. Geophysical Monograph 195. American Geophysical Union, Washington DC, pp. 117-130.

Hamilton, P., Donohue, K. A., Hall, C., Leben, R., Quian, H., Sheinbaum, J., Watts, D., 2014. Observations and Dynamics of the Loop Current, OCS Study BOEM 5015-006, 417 p. New Orleans, LA.

Hamilton, P., Lugo-Fernández, A., Sheinbaum, A. J., 2015. A Loop Current experiment: Field and remote measurements. Dynamics of Atmosphere and Ocean. submitted to, this issue.

Howden, S. D., 2000. The three dimensional secondary circulation in developing Gulf Stream meanders. J. Phys. Oceanogr. 30, 888-915.

Huang, H., Walker, N. D., Hsueh, Y., Chao, Y., Leben, R. R., 2013. An analysis of Loop Current frontal eddies in a $\frac{1}{6}^{\circ}$ Atlantic Ocean model simulation. J. Phys. Oceanogr. 43, 1924-1939.

Hurlburt, H., Thompson, J. D., 1980. A numerical study of Loop Current intrusions and eddy shedding. J. Phys. Oceanogr. 10 (10), 1611-1651.

Hurlburt, H. E., 1986. Dynamic transfer of simulated altimeter data into subsurface information by a numerical ocean model. J. Geophys. Res. 91, 2372-2400.

Le Hénaff, M., Kourafalou, V. H., Morel, Y., Srinivasan, A., 2012. Simulating the dynamics and intensification of cyclonic Loop Current Frontal Eddies in the Gulf of Mexico. J. Geophys. Res. 117, C02034. 
Leben, R., 2005. Altimeter-derived Loop Current metrics. In: Sturges, W., Lugo-Fernández, A. (Eds.), Circulation in the Gulf of Mexico: observations and models. American Geophysical Union, Washington, D.C., pp. 181-202.

Leben, R. R., Born, G. H., Engebreth, B. R., 2002. Operational altimeter data processing for mesoscale monitoring. Marine Geodesy 25, 3-18.

Lindstrom, S. S., Watts, D. R., 1994. Vertical motion in the Gulf Stream near $68^{\circ} \mathrm{W}$. J. Phys. Oceanogr. 24, 2321-2333.

Liu, Y., MacFadyen, A., Ji, Z.-G., Weisberg, R. (Eds.), 2011a. Monitoring and modeling the Deepwater Horizon oil spill: a record-breaking enterprise. Geophysical Monograph 195. American Geophysical Union, Washington DC.

Liu, Y., Weisberg, R. H., Hu, C., Kovach, C., Riethmüller, R., 2011b. Evolution of the Loop Current System during the Deepwater Horizon Oil Spill Event as observed with drifters and satellites. In: Y. Liu, A. MacFadyen, Z.-G. J., Weisberg, R. (Eds.), Monitoring and modeling the Deepwater Horizon oil spill: a record-breaking enterprise. Geophysical Monograph 195. American Geophysical Union, Washington DC, pp. 91-101.

Marshall, J., Shutts, G., 1981. A note on rotational and divergent eddy fluxes. J. Phys. Oceanogr. 11 (12), 1677-1680.

Meinen, C. S., Watts, D. R., 2000. Vertical structure and transport on a transect across the North Atlantic Current near 42 N: Time series and mean. J. Geophys. Res. 105, 21869-21891. 
Nof, D., Pichevin, T., 2001. The ballooning of outflows. J. Phys. Oceanogr. 31 (10), 3045-3058.

Oey, L., 2008. Loop current and deep eddies. J. Phys. Oceanogr. 38, 14261449 .

Oey, L., Lee, H., 2002. Deep eddy energy and topographic Rossby waves in the Gulf of Mexico. J. Phys. Oceanogr. 32 (12), 3499-3527.

Oey, L.-Y., 2004. Vorticity flux through the Yucatan Channel and Loop Current variability in the Gulf of Mexico. J. Geophys. Res. 109 (C10), C10004.

Oey, L.-Y., Lee, H.-C., Schmitz, W. J., 2003. Effects of winds and Caribbean eddies on the frequency of Loop Current eddy shedding: A numerical model study. J. Geophys. Res. 108 (C10), 3324.

Park, J.-H., Watts, D. R., Donohue, K. A., Tracey, K. L., 2012. Comparisons of sea surface height variability observed by pressure-recording inverted echo sounders and satellite altimetry in the Kuroshio Extension. J. of Oceanogr. 68 (3), 401-416.

Pichevin, T., Nof, D., 1997. The momentum imbalance paradox. Tellus A 49 (2), 298-319.

Schmitz, W. J., 2005. Cyclones and westward propagation in the shedding of anticyclonic rings from the Loop Current. In: Sturges, W., LugoFernández, A. (Eds.), Circulation in the Gulf of Mexico: observations and models. American Geophysical Union, Washington, D.C., pp. 241-261. 
Shay, L. K., Jaimes, B., Brewster, J. K., Meyers, P., McCaskill, E. C., Uhlhorn, E., Marks, F., Halliwell Jr, G. R., Smedstad, O. M., Hogan, P., 2011. Airborne ocean surveys of the Loop Current complex from NOAA WP-3D in support of the Deepwater Horizon oil spill. In: Y. Liu, A. MacFadyen, Z.-G. J., Weisberg, R. (Eds.), Monitoring and modeling the Deepwater Horizon oil spill: a record-breaking enterprise. Geophysical Monograph 195. American Geophysical Union, Washington DC, pp. 131-151.

Sturges, W., Leben, R., 2000. Frequency of ring separations from the Loop Current in the Gulf of Mexico: A revised estimate. J. Phys. Oceanogr. $30(7), 1814-1819$.

Vukovich, F. M., Maul, G. A., 1985. Cyclonic eddies in the eastern Gulf of Mexico. J. Phys. Oceanogr. 15, 105-117.

Walker, N., Pilley, C., Raghunathan, V., D’Sa, E., Leben, R., Hoffman, N., Brickley, P., Coholan, P., Sharma, N., Graber, H., Turner, R., 2011. Impacts of Loop Current frontal cyclonic eddies and wind forcing on the 2010 Gulf of Mexico oil spill. In: Y. Liu, A. MacFadyen, Z.-G. J., Weisberg, R. (Eds.), Monitoring and modeling the Deepwater Horizon oil spill: a recordbreaking enterprise. Geophysical Monograph 195. American Geophysical Union, Washington DC, pp. 103-116.

Welch, P. D., 1967. The use of the fast Fourier transform for the estimation of power spectra: A method based on time averaging over short, modified periodograms. IEEE Trans. Audio Electroacoustics AU-15 (2), 70-73. 
677 Welsh, S. E., Inoue, M., 2000. Loop Current rings and the deep circulation 678 in the Gulf of Mexico. J. Geophys. Res. 105 (C7), 16951-16959.

679 Zavala-Hidalgo, J., Morey, S. L., O'Brien, J. J., 2003. Cyclonic eddies north680 east of the Campeche Bank from altimetry data. J. Phys. Oceanogr. 33, 681 623-629. 


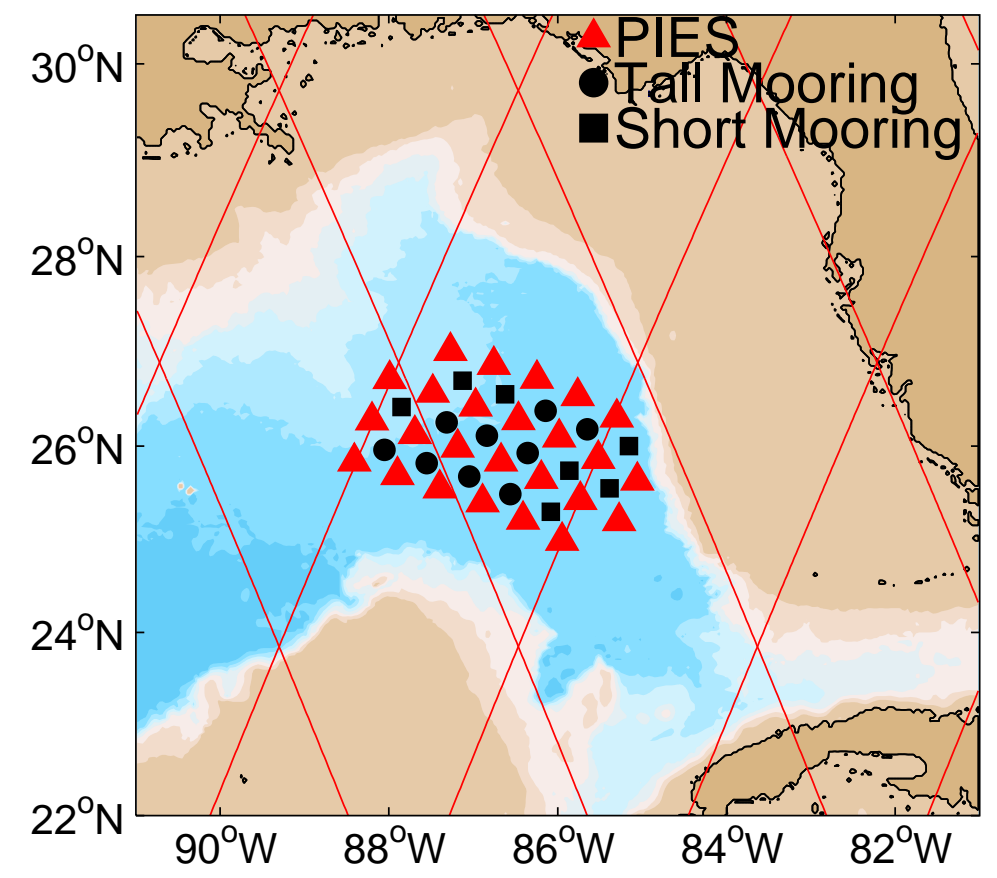

Figure 1: Dynamics of the Loop Current Array consisted of 25 pressure inverted echo sounders, PIES, (red triangle), 9 tall moorings (black circles) and 7 short moorings (black squares). Bathymetry contoured every $1000 \mathrm{~m}$ depth, deepest topography denoted by the darkest blue hues. Jason-2 altimetry tracks shown in red. 
Ekman
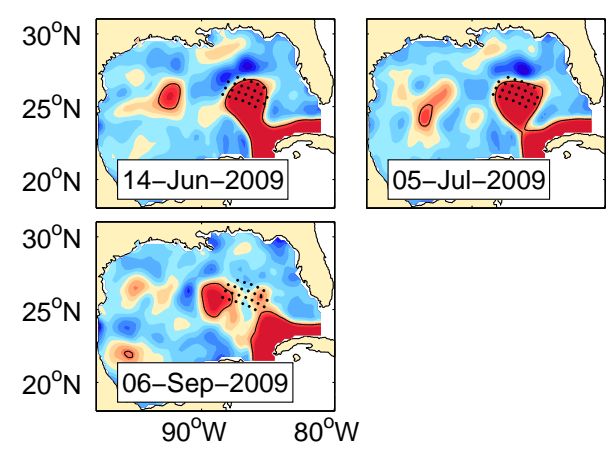

Franklin

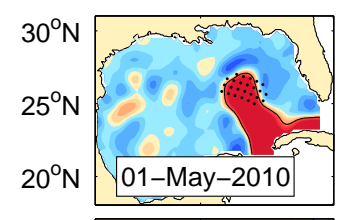

$30^{\circ} \mathrm{N}$

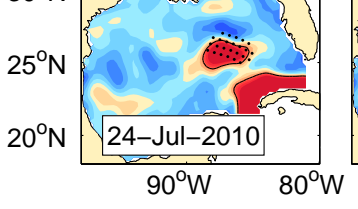

Hadal

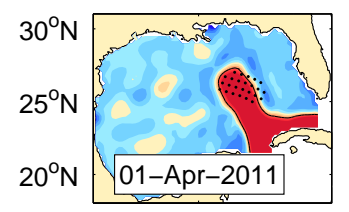

$30^{\circ} \mathrm{N}$

$25^{\circ} \mathrm{N}$

$20^{\circ} \mathrm{N}$
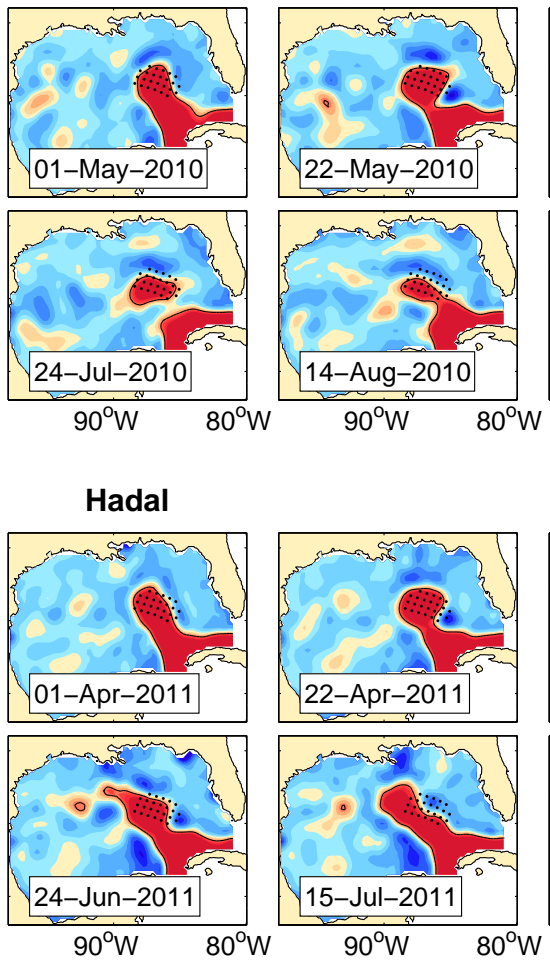
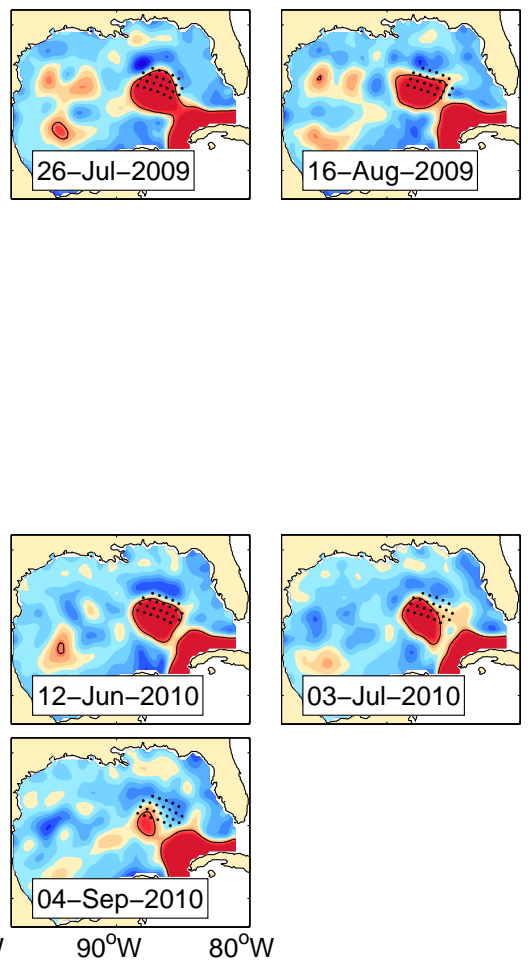

03-Jul-2010$$
\text { (1) }
$$
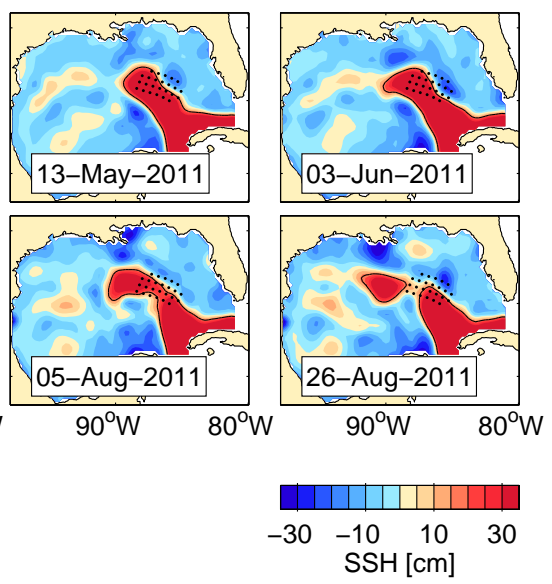

Figure 2: Sea surface height fields at 21-day intervals during the three Loop Current Eddy separations which occurred during the Dynamics of the Loop Current experiment. PIES locations are shown as black dots in each panel. Mapped SSH determined from the Colorado Center for Atmospheric Research (CCAR) Gulf of Mexico objectively mapped historical mesoscale altimeter data reanalysis. Date noted in the lower left of each panel. $\mathrm{SSH}$ contour interval is $5 \mathrm{~cm}$. 

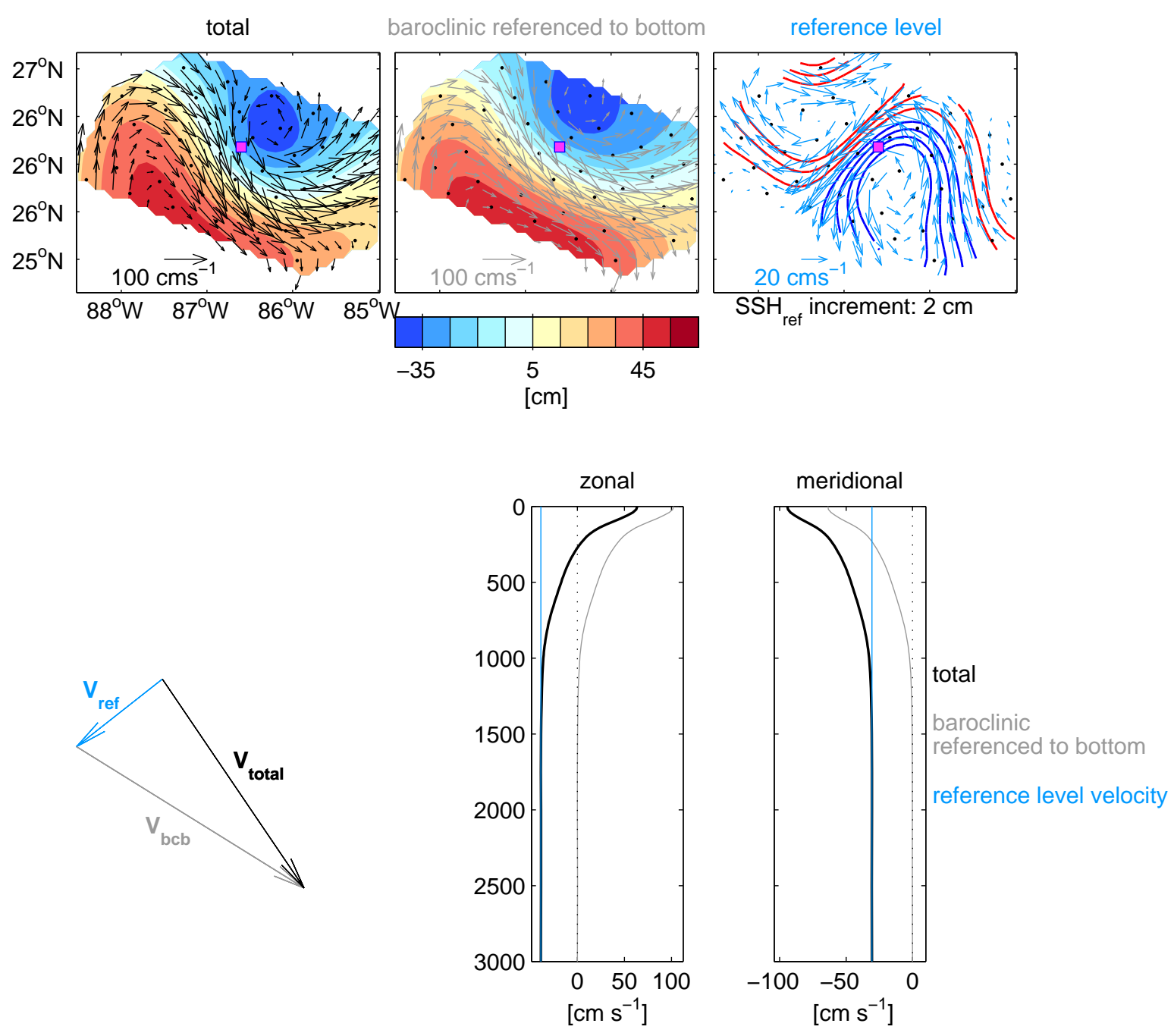

Figure 3: Several views of the circulation on June 24, 2010 provided by the PIES and current meter measurements. Top panels: Total sea surface height in plan view (left), displaying its baroclinic contribution referenced to the bottom (middle) and reference level contribution (right). Anticyclonic circulations shown by reddish hues; cyclonic circulations by bluish hues. Mapped current vectors plotted at $20 \mathrm{~km}$ spacing. PIES and current meter sites denoted by black circles. Bottom left panel: The vector sum of deep reference velocity (blue arrow) and baroclinic referenced to the bottom velocity (gray arrow) produces the total velocity. A baroclinic velocity profile that is vertically aligned like this is called equivalent barotropic. Bottom two right panels: Zonal and meridional velocity (total is black, reference level velocity is blue, and baroclinic referenced to the bottom is gray) at the magenta square shown in the upper panels. 
a) 200 m eddy kinetic energy

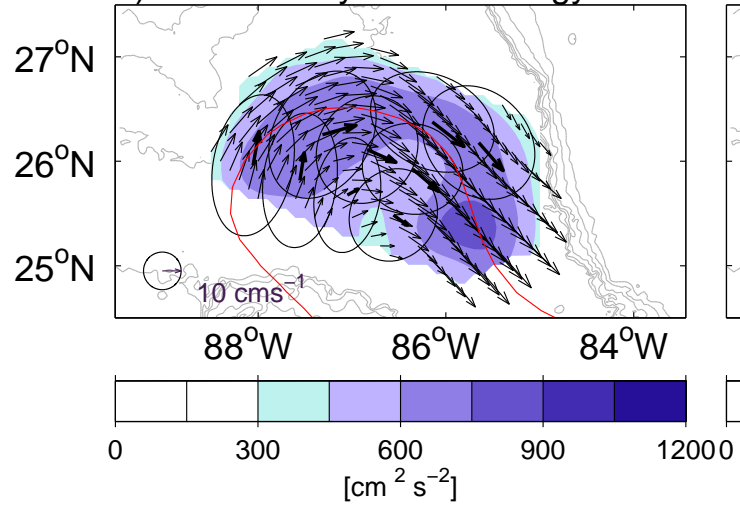

b) near-bottom eddy kinetic energy

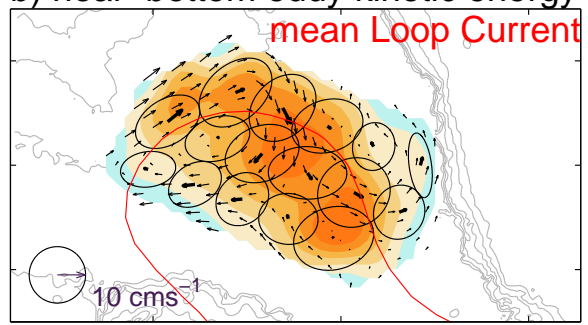

$88^{\circ} \mathrm{W} \quad 86^{\circ} \mathrm{W} \quad 84^{\circ} \mathrm{W}$

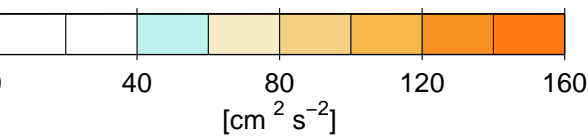

c) $200 \mathrm{~m}$ depth eddy kinetic energy
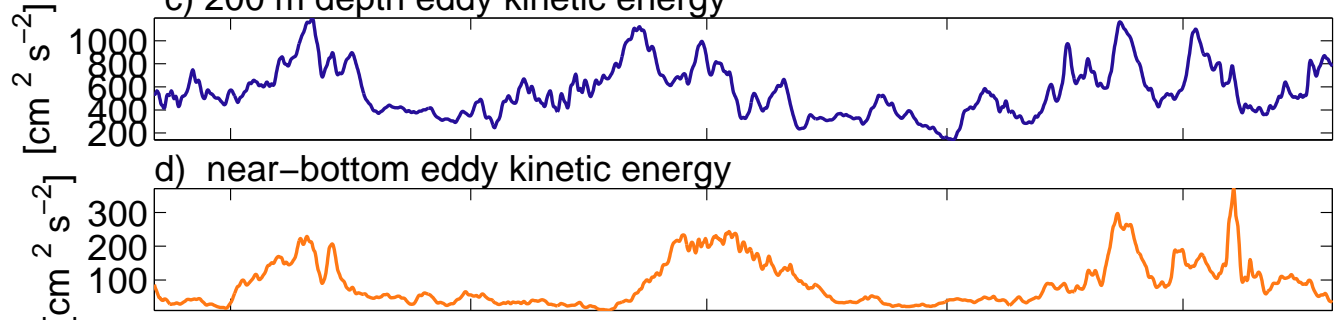

ह

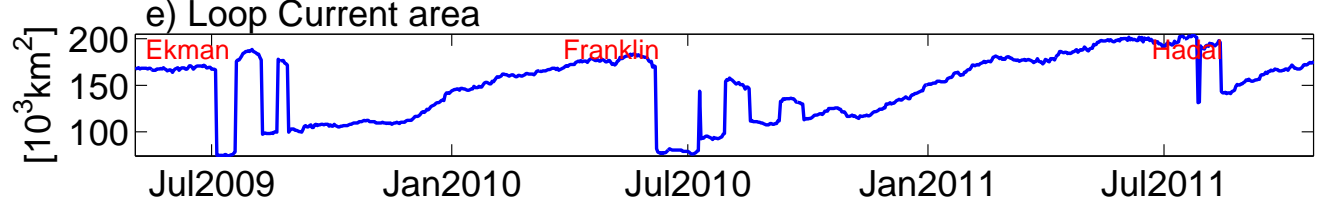

Figure 4: Mapped and directly measured mean currents (respectively thin and bold vectors) for $200 \mathrm{~m}$ level (panel a) and near bottom (panel b). Standard deviation ellipses superimposed on the time-mean eddy kinetic energy (color-bar, $\mathrm{cm}^{2} \mathrm{~s}^{-2}$ ). Scale for vectors and ellipses shown in lower left corner. Red line denotes the mean Loop Current position defined by the CCAR-SSH $17 \mathrm{~cm}$ contour. Bathymetry plotted with gray contours every $500 \mathrm{~m}$ depth. Time mean is taken over the 30-month experiment duration from May 3, 2009 through October 23, 2011. Panels c and d: Time series of array-averaged $200 \mathrm{~m}$ (panel c) and near-bottom (panel d) eddy kinetic energy in units of $\mathrm{cm}^{2} \mathrm{~s}^{-2}$. Panel e: Time series of array-average CCAR-SSH derived Loop Current area in units of $10^{3} \mathrm{~km}^{2}$. 

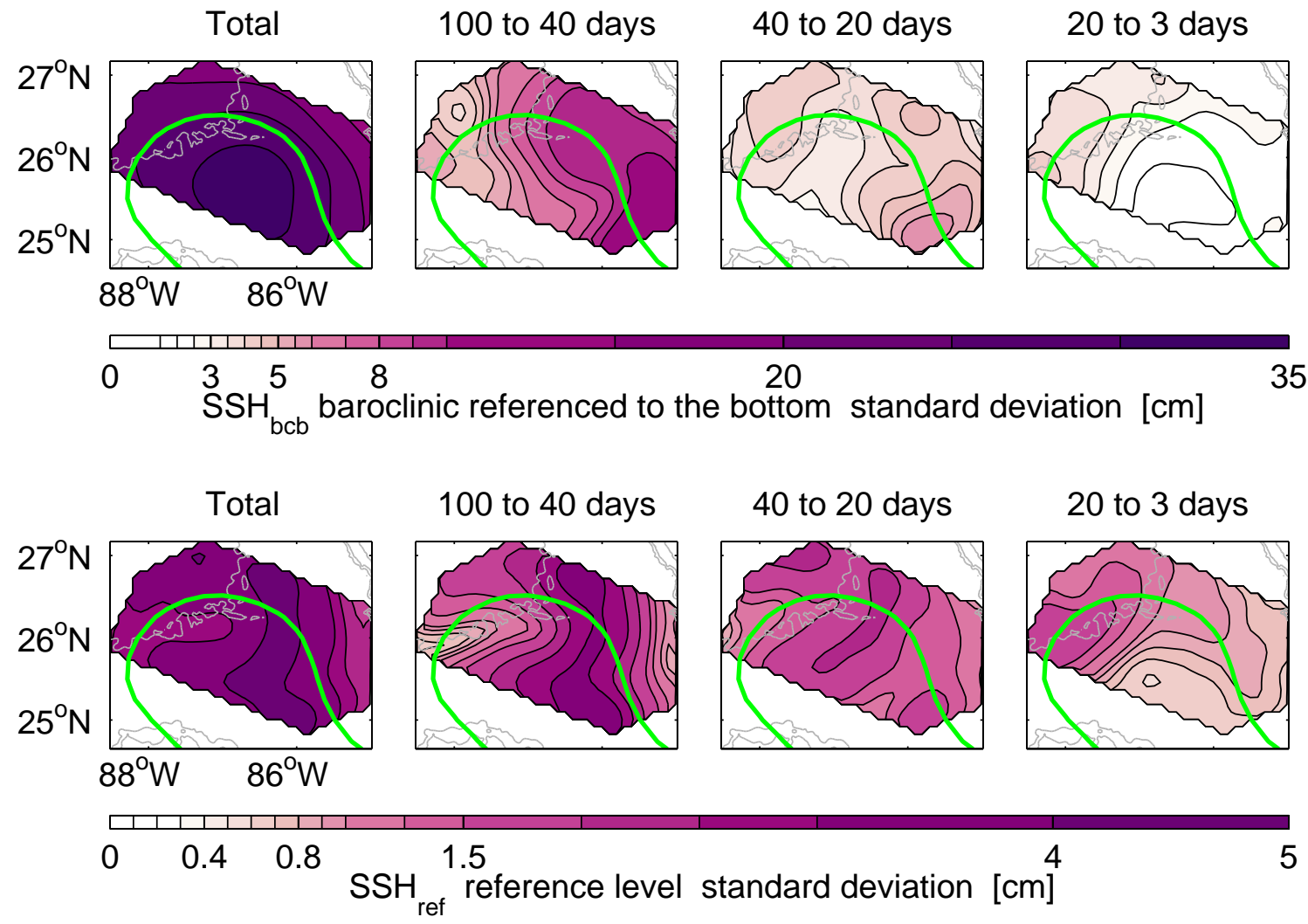

Figure 5: Standard deviation of $\mathrm{SSH}_{b c b}$ (top panels) and $\mathrm{SSH}_{r e f}$ (bottom panels) as a function of frequency band. Leftmost panels show total standard deviation. Three right panels: Standard deviation in three frequency bands noted above each panel. Bathymetry contoured in gray every $500 \mathrm{~m}$ depth. Note that the colorbar contour interval is not uniform. 


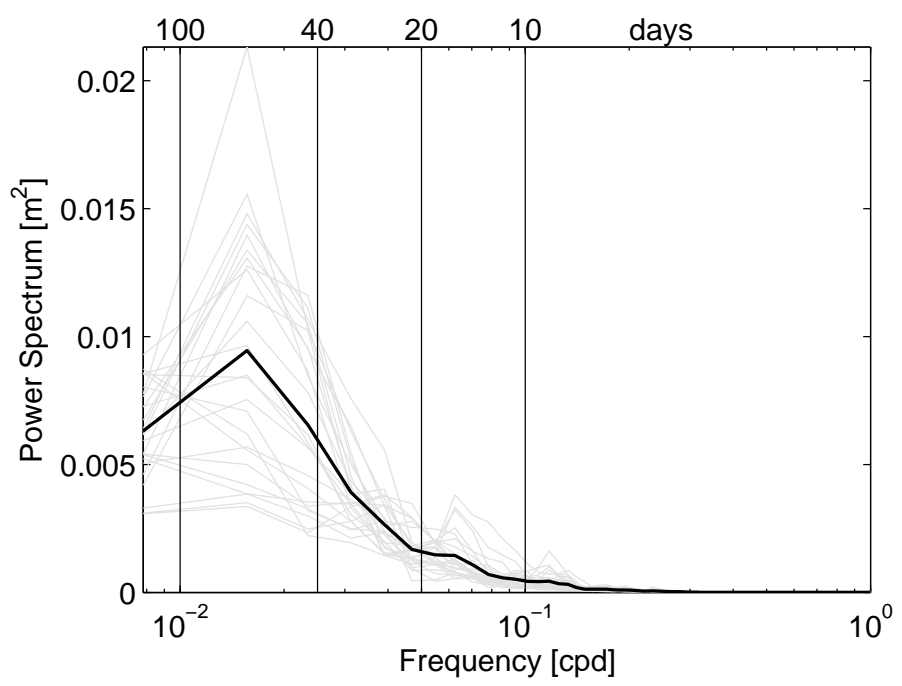

Figure 6: Variance-preserving power spectrum for individual (gray) and array-averaged (black) PIES $\mathrm{SSH}_{b c b}$. Frequency limits that define the frequency bands evaluated in Figure 5 are denoted with vertical black lines. 

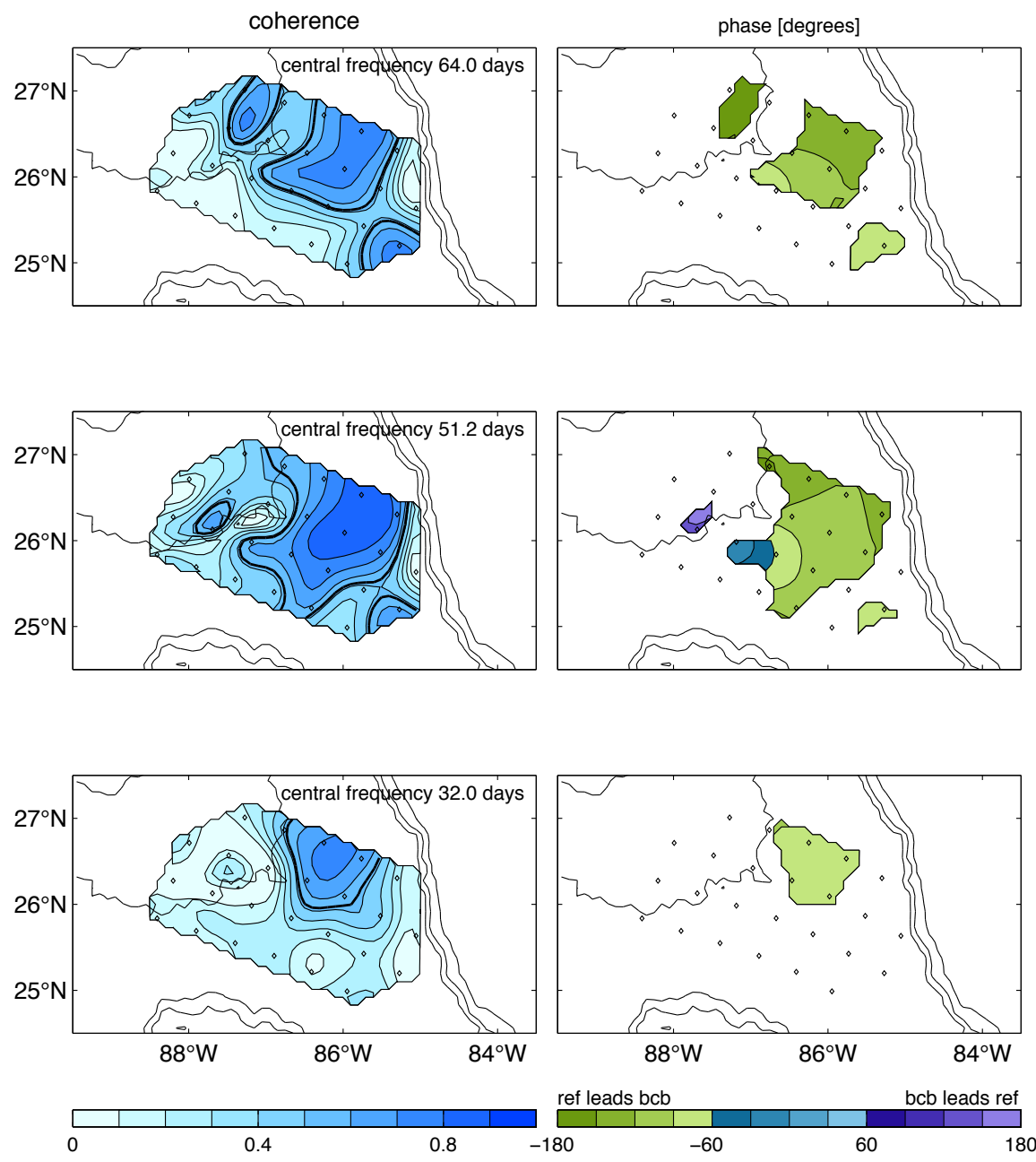

Figure 7: Coherence (left) and phase (right) between upper, $\mathrm{SSH}_{b c b}$, and lower, $\mathrm{SSH}_{r e f}$, streamfunction for three frequency bands: top $\left(1 / 64 \mathrm{~d}^{-1}\right)$, middle $\left(1 / 51.2 \mathrm{~d}^{-1}\right)$, and bottom $\left(1 / 32 \mathrm{~d}^{-1}\right)$, estimated using Welch's averaged periodogram method (256-day length segment with $50 \%$ overlap). Phase (in degrees) contoured where coherence exceeds $95 \%$ confidence limits denoted by the thick black contour in the coherence maps. Negative phase indicates that deep leads upper. PIES locations shown by black diamonds. Bathymetry (thin black line) contoured every $1000 \mathrm{~m}$ depth. 


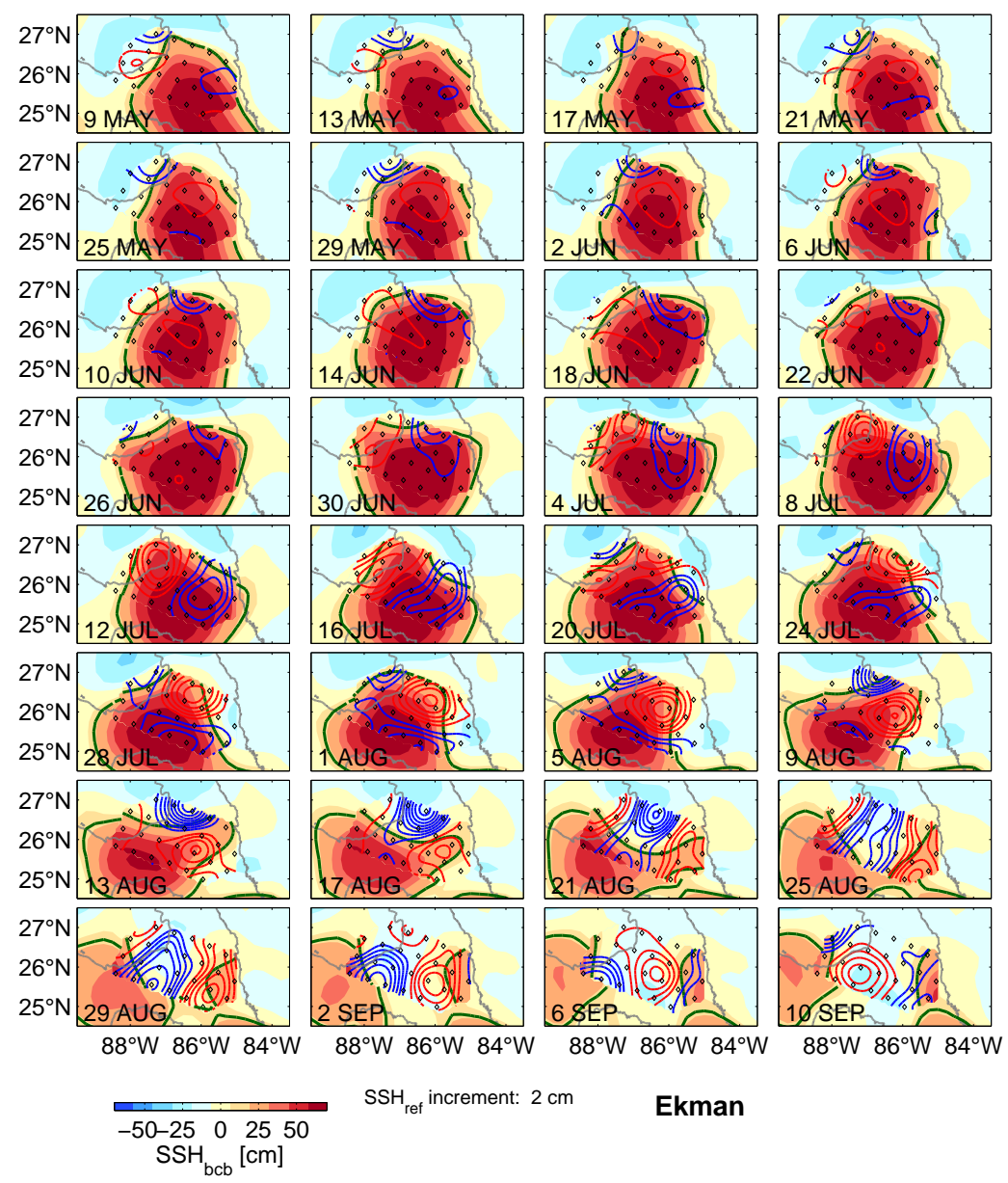

Figure 8: Loop Current Eddy shedding event Ekman May 9 through September 102009. Maps of baroclinic SSH referenced to the bottom $\left(\mathrm{SSH}_{b c b}\right)$ embedded within altimetric SSH (filled color contours; colorbar and contour interval in the bottom left figure corner). Maps shown sequentially left to right, top to bottom at 4-day intervals. The $17 \mathrm{~cm}$ contour (bold green, $\mathrm{SSH}_{b c b}$ within array, altimetric $\mathrm{SSH}$ outside array) denotes the location of the Loop Current. Mapped reference level SSH $\left(\mathrm{SSH}_{r e f}\right)$ reveals the presence of deep cyclones (thin blue contours) and anticyclones (thin red contours) contoured every $2 \mathrm{~cm}$. Diamonds denote PIES sites. Gray lines denote the $3000 \mathrm{~m}$ depth contour. 


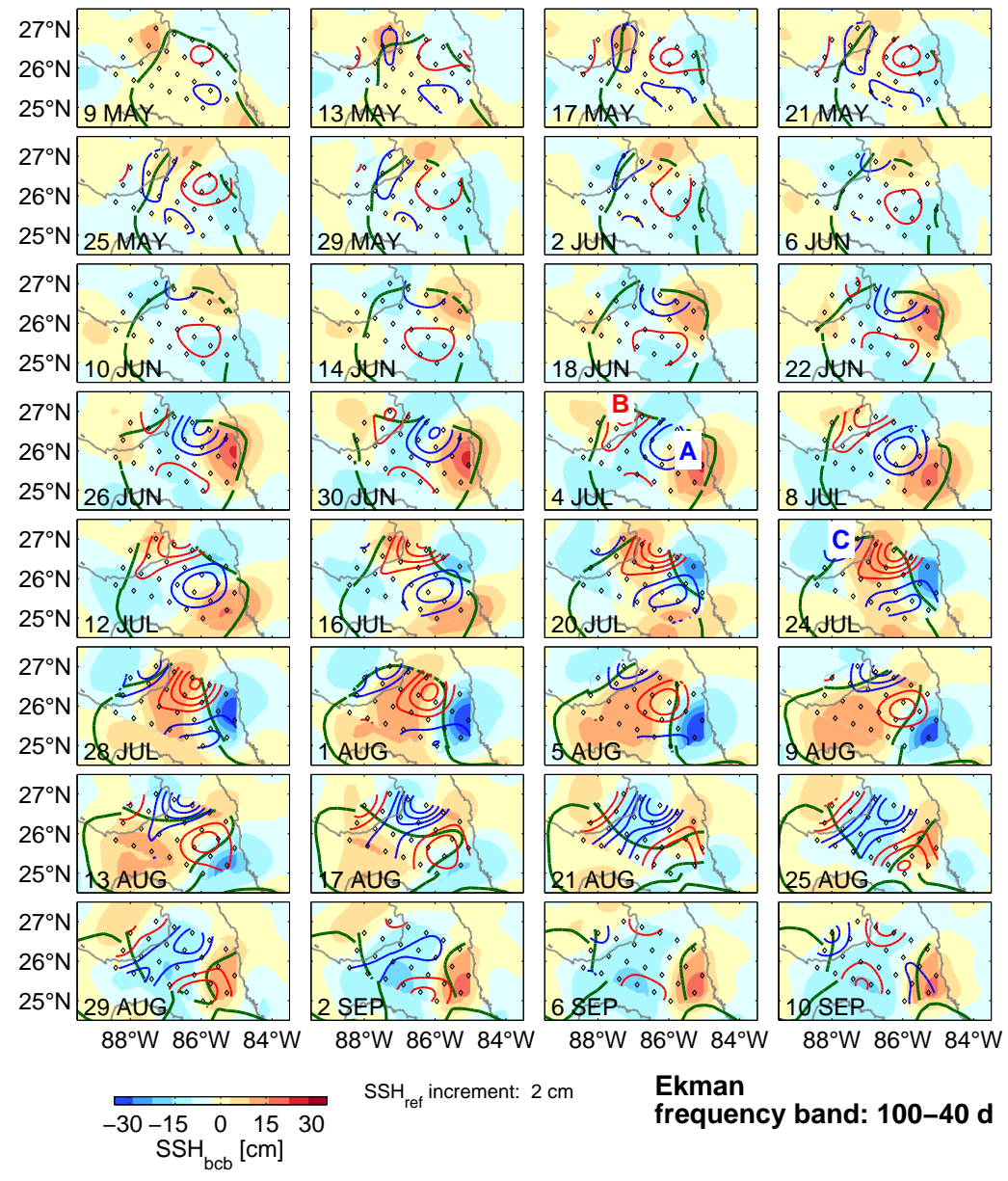

Figure 9: Loop Current Eddy shedding event Ekman May 9 through September 102009. Maps of 100-40 day band-passed baroclinic SSH referenced to the bottom $\left(\mathrm{SSH}_{b c b}\right)$ embedded within altimetric SSH (filled color contours; colorbar and contour interval in the bottom left figure corner). Maps shown sequentially left to right, top to bottom at 4 day intervals. The $17 \mathrm{~cm}$ contour (bold green, $\mathrm{SSH}_{b c b}$ within array, altimetric SSH outside array) denotes the location of the Loop Current. Mapped 100-40 day band-passed reference level SSH ( $\mathrm{SSH}_{r e f}$ ) reveals the presence of deep cyclones (thin blue contours) and anticyclones (thin red contours) contoured every $2 \mathrm{~cm}$. Diamonds denote PIES sites. Gray lines denote the $3000 \mathrm{~m}$ depth contour. The July 4 map indicates deep cyclone A and deep anticyclone B discussed in the text. The July 24 map indicates deep cyclone C discussed in the text. 


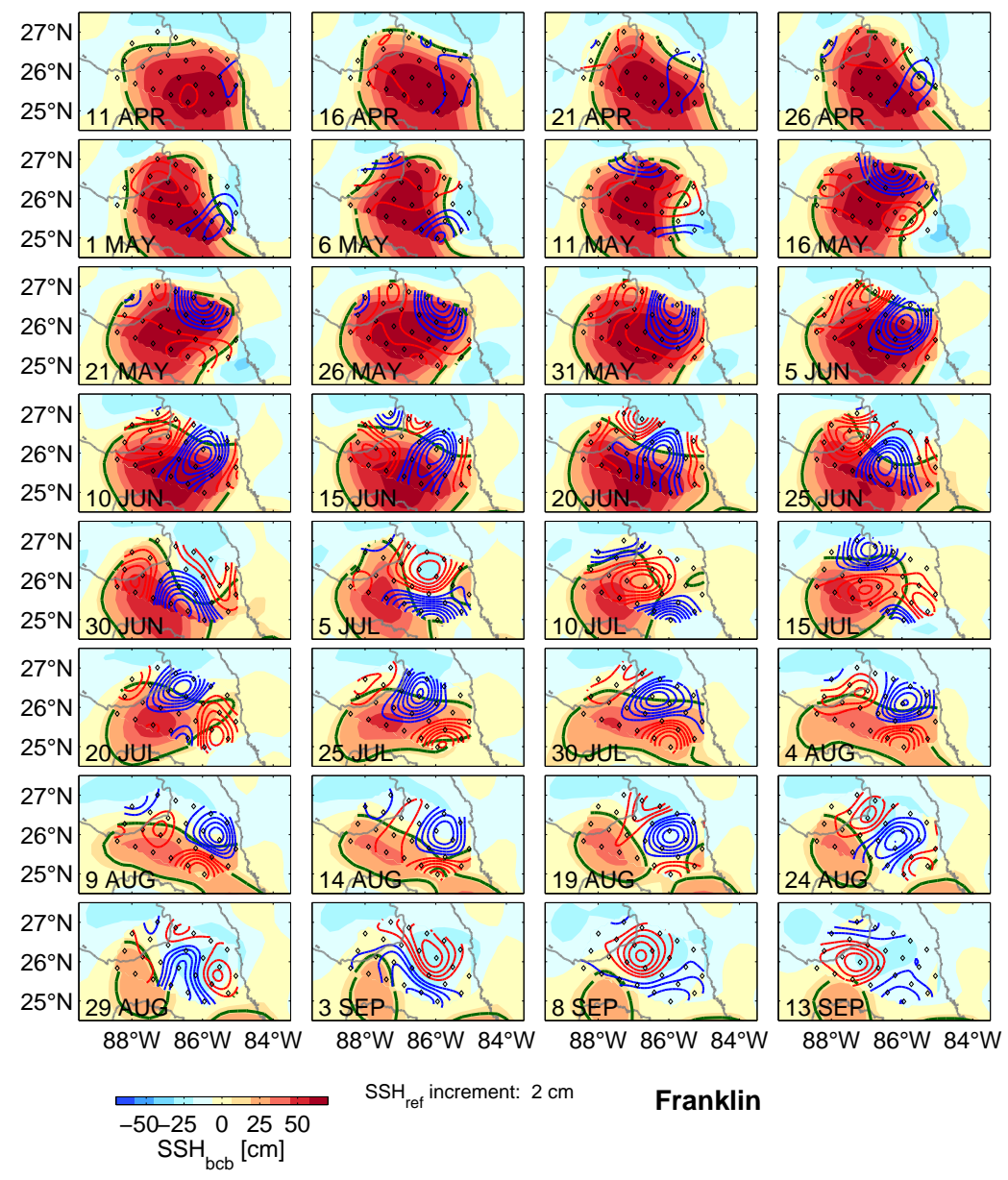

Figure 10: Same as Figure 8, for Loop Current Eddy shedding event Franklin April 11 through September 13, 2010. 


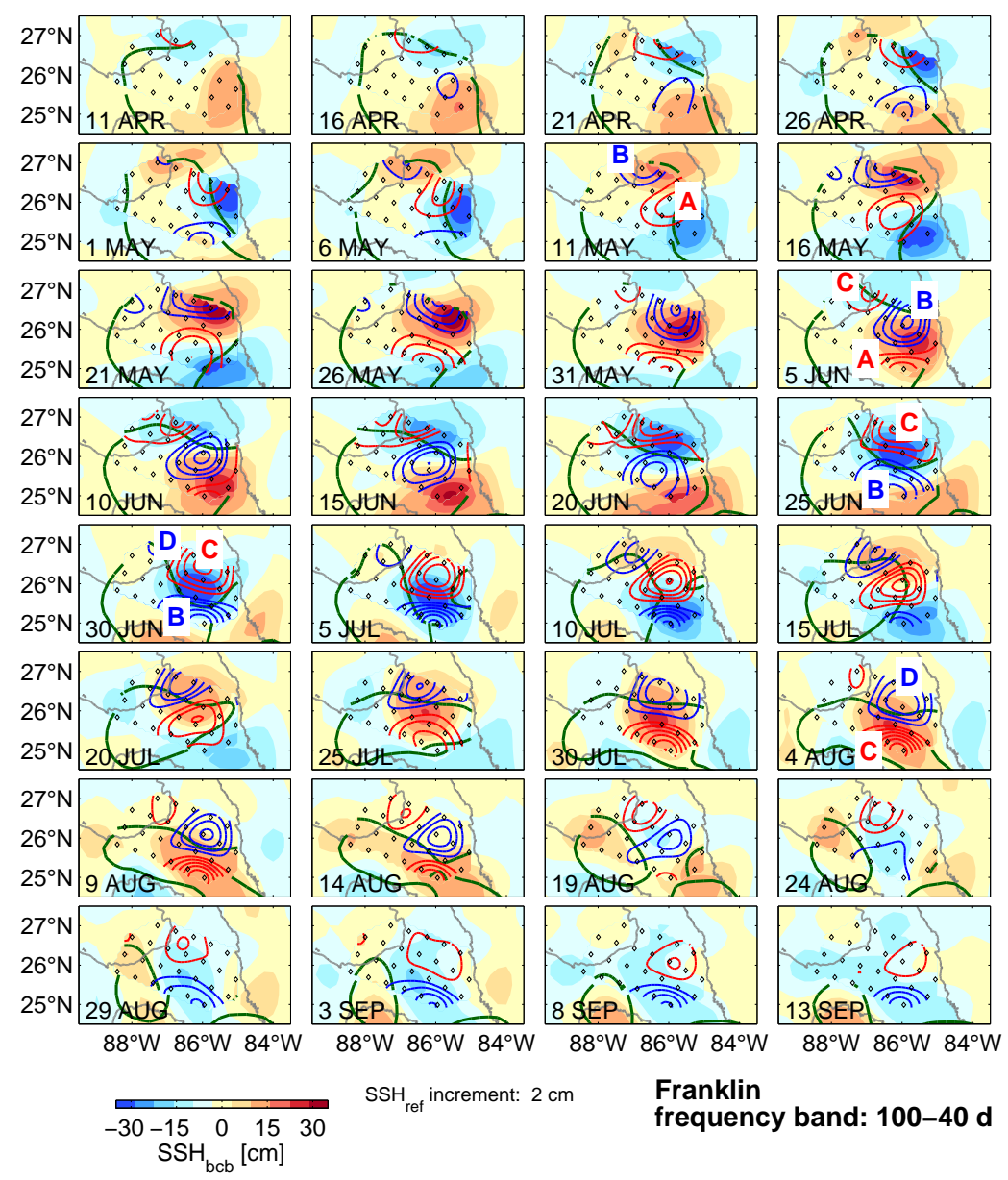

Figure 11: Same as Figure 9, for Loop Current Eddy shedding event Franklin April 11 through September 13, 2010. The May 11 map indicates deep anticyclone A and deep cyclone B discussed in the text. The June 5 map indicates deep anticyclone $\mathrm{C}$ discussed in the text. The June 30 map indicates deep cyclones B, D and deep anticyclone C discussed in the text. The August 4 map also indicates deep cyclone D and deep anticyclone C. 


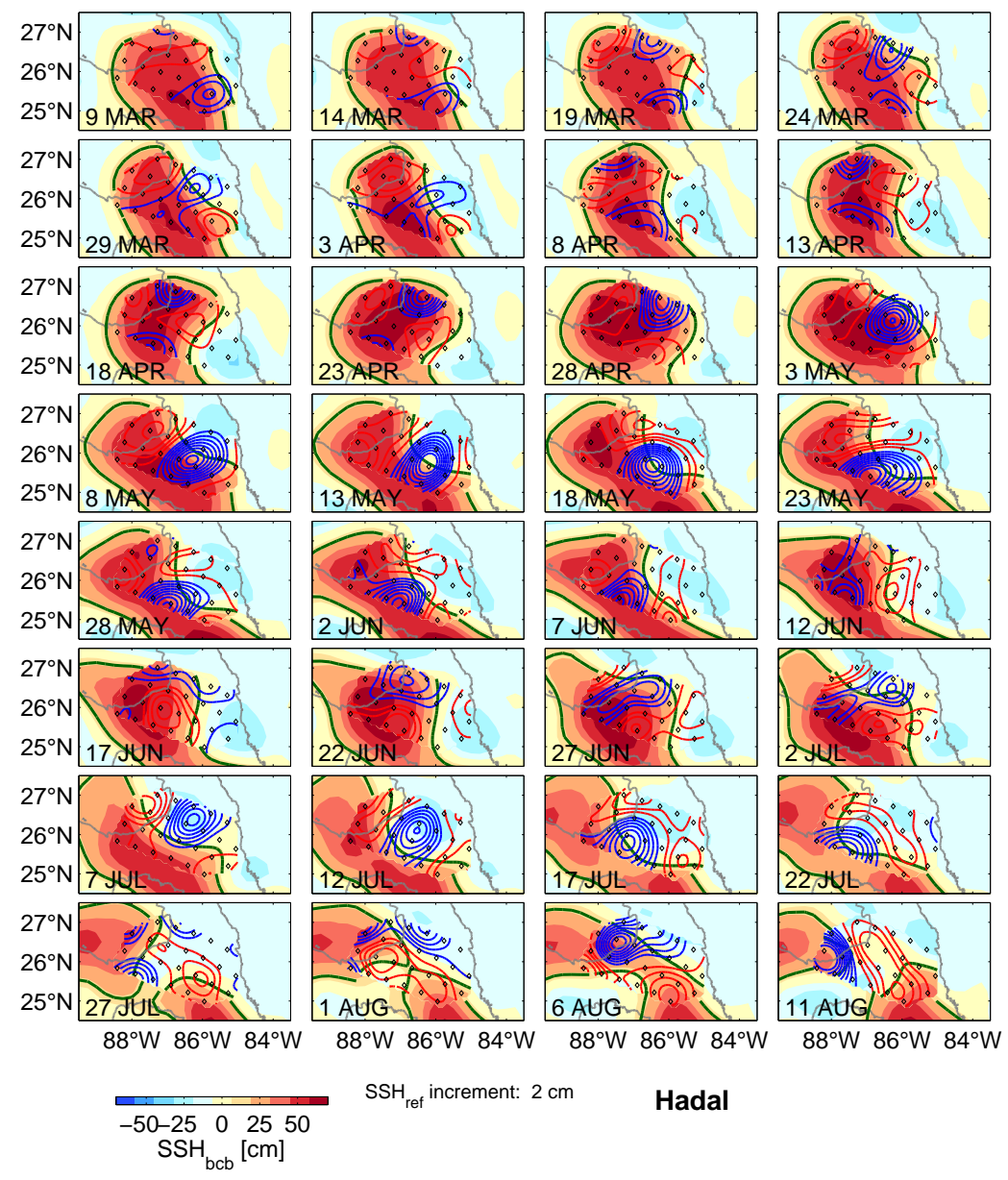

Figure 12: Same as Figure 8, Loop Current Eddy shedding event Hadal March 9 through August 11, 2011. 


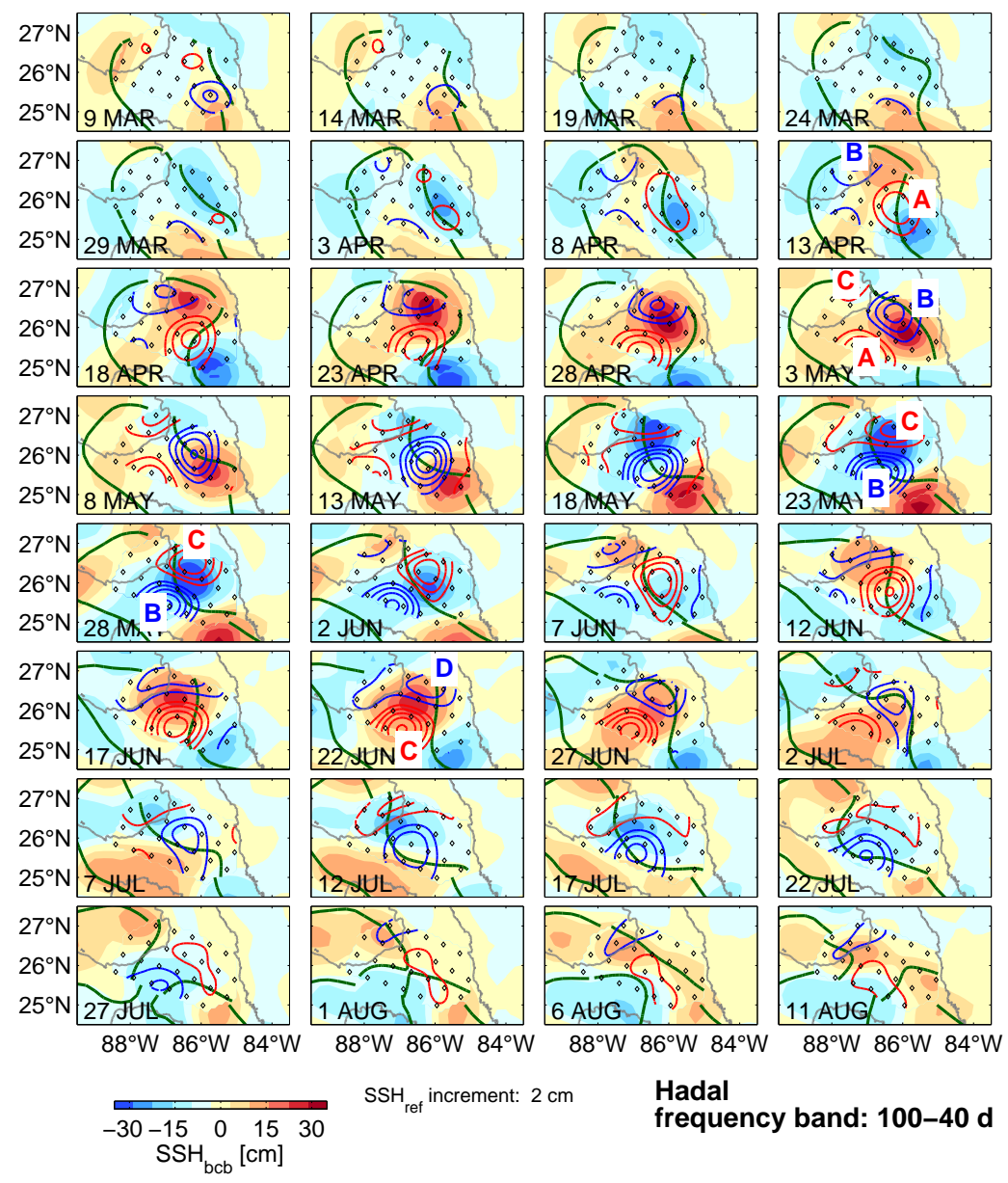

Figure 13: Same as Figure 9, Loop Current Eddy shedding event Hadal March 9 through August 11, 2011. The April 13, May 3 and May 23 maps indicate deep anticyclone A, deep cyclone B, and deep anticyclone C, respectively. The May 28 map indicates deep cyclone B and deep anticyclone $\mathrm{C}$ discussed in the text. The June 22 map indicates the deep cyclone D discussed in the text. 


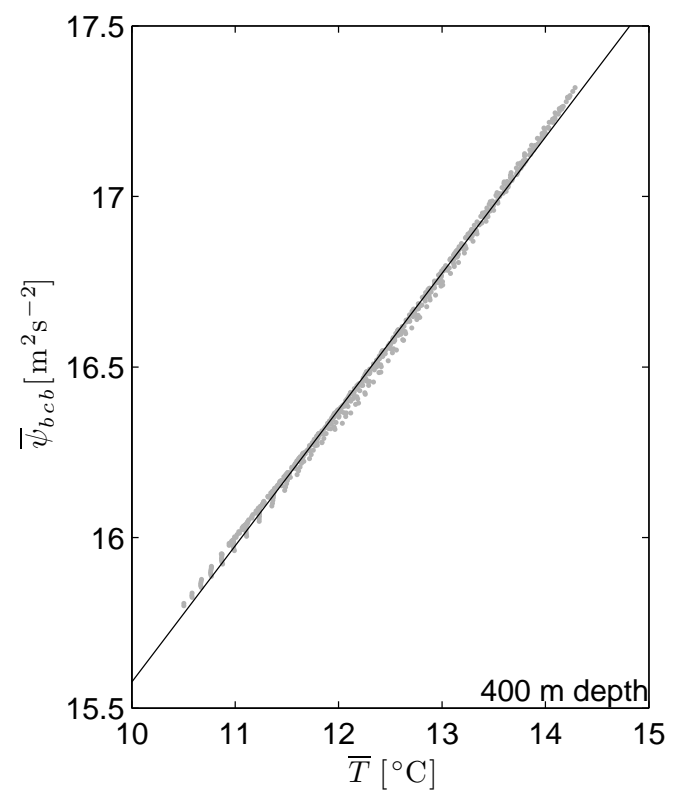

Figure 14: A nearly linear relationship (black line) exists between between mean $\psi_{b c b}$ and mean $\mathrm{T}$ at $400 \mathrm{~m}$ (gray dots). 

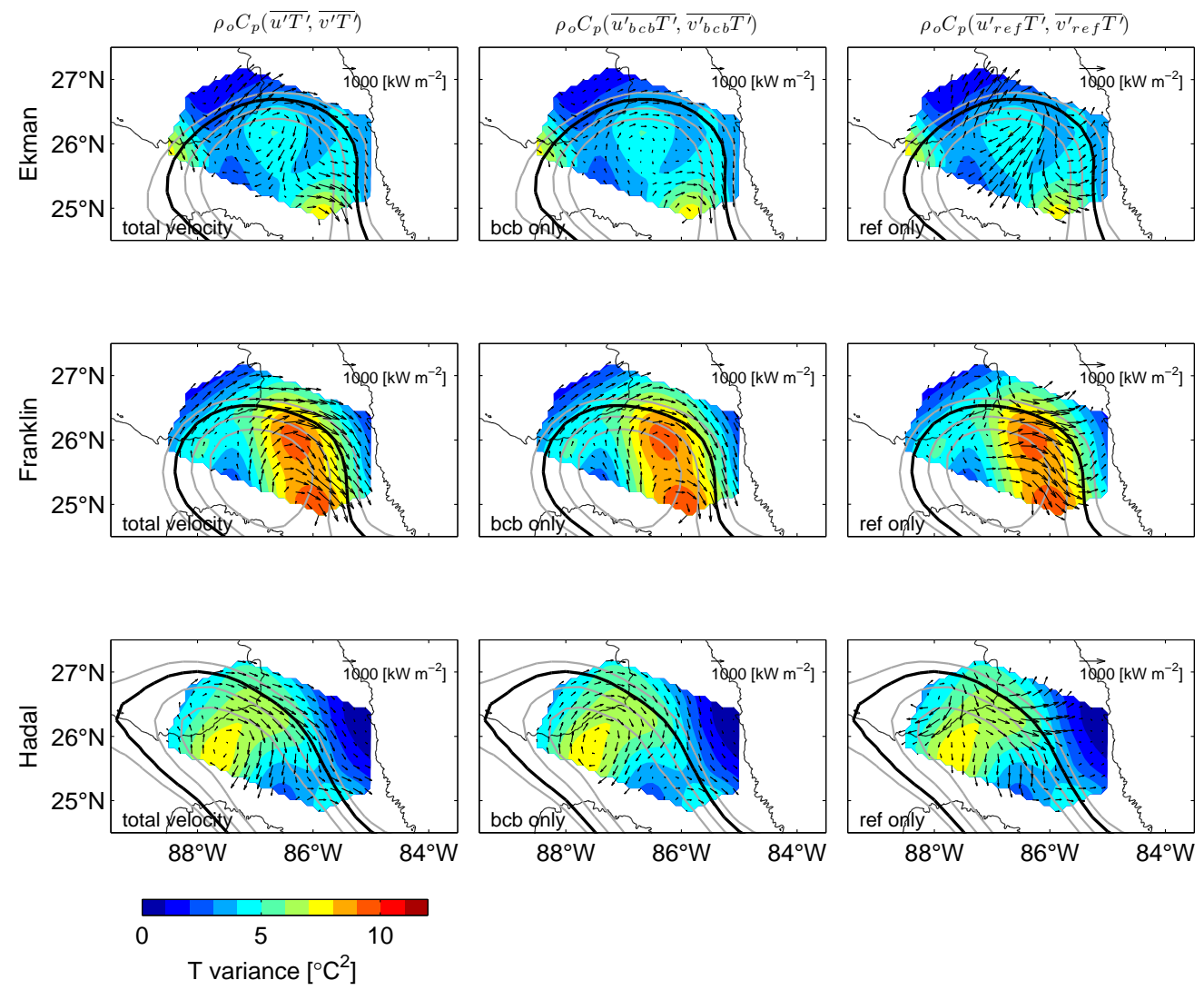

T variance $\left[{ }^{\circ} \mathrm{C}^{2}\right]$

Figure 15: Eddy heat flux vectors at $400 \mathrm{~m}$ depth for the three Loop Current Eddy shedding events superimposed on the $400 \mathrm{~m}$ depth temperature variance (same across each row). Rows correspond to time averages over the Loop Current Eddy shedding events: Ekman May 3 through August 31, 2009 (top), Franklin February 15 through September 14, 2010 (middle), Hadal March 1 through September 14, 2011 (bottom). Columns correspond to the perturbation velocity used in the eddy heat flux calculation: total (left), baroclinicreferenced-to-the-bottom (center), reference (right). The bold black line denotes the mean position of the $17 \mathrm{~cm}$ altimeter-mapped SSH contour; gray contours indicate the 10, 27, and $37 \mathrm{~cm}$ contour. The $3000 \mathrm{~m}$ isobath contoured with thin black line. 


\section{Ekman May.03,2009 through Aug.31,2009 400 m depth}
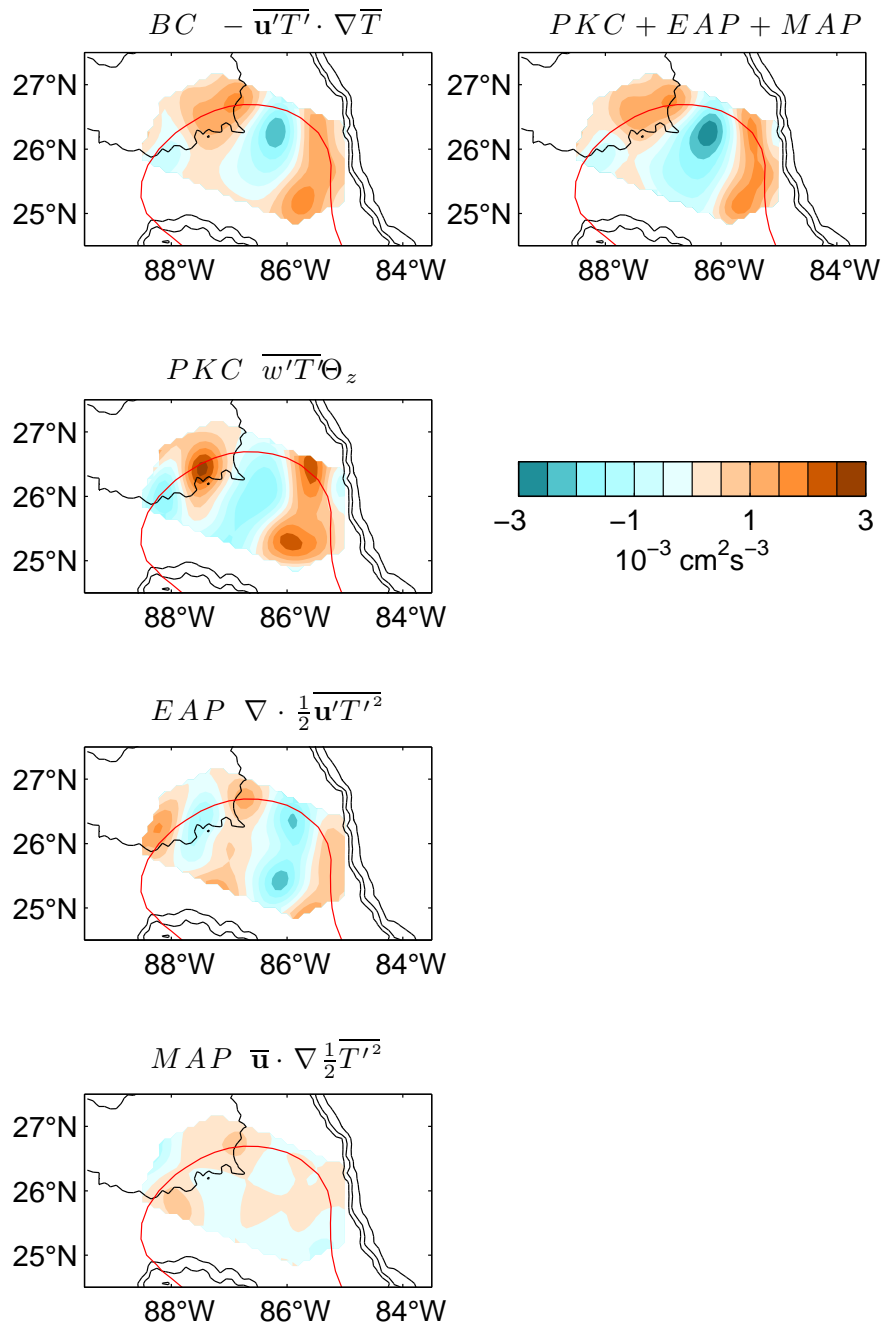

Figure 16: Four terms in the steady eddy potential energy budget (Eqn 15) determined for the Ekman event May 3 through August 31, 2009 at $400 \mathrm{~m}$ depth (contour interval after multiplication by $g \alpha / \Theta_{z}=428 \mathrm{~cm}^{2} \mathrm{~s}^{-2 \circ} \mathrm{C}^{-2}$ is $0.5 \times 10^{-3} \mathrm{~cm}^{2} \mathrm{~s}^{-3}$; in colorbar blues hues are negative and orange hues are positive). The horizontal downgradient eddy heat flux (BC) is balanced by the mean advection of eddy potential energy (MAP), eddy advection of eddy potential energy (EAP) and the vertical downgradient heat flux (PKC). Right panel shows the sum of the PKC, EAP and MAP terms. The red line denotes the mean position of the $17 \mathrm{~cm}$ altimeter-mapped SSH contour. Bathymetry (thick black lines) contoured every $1000 \mathrm{~m}$ depth. 
Ekman May.03,2009 through Aug.31,2009 400 m depth
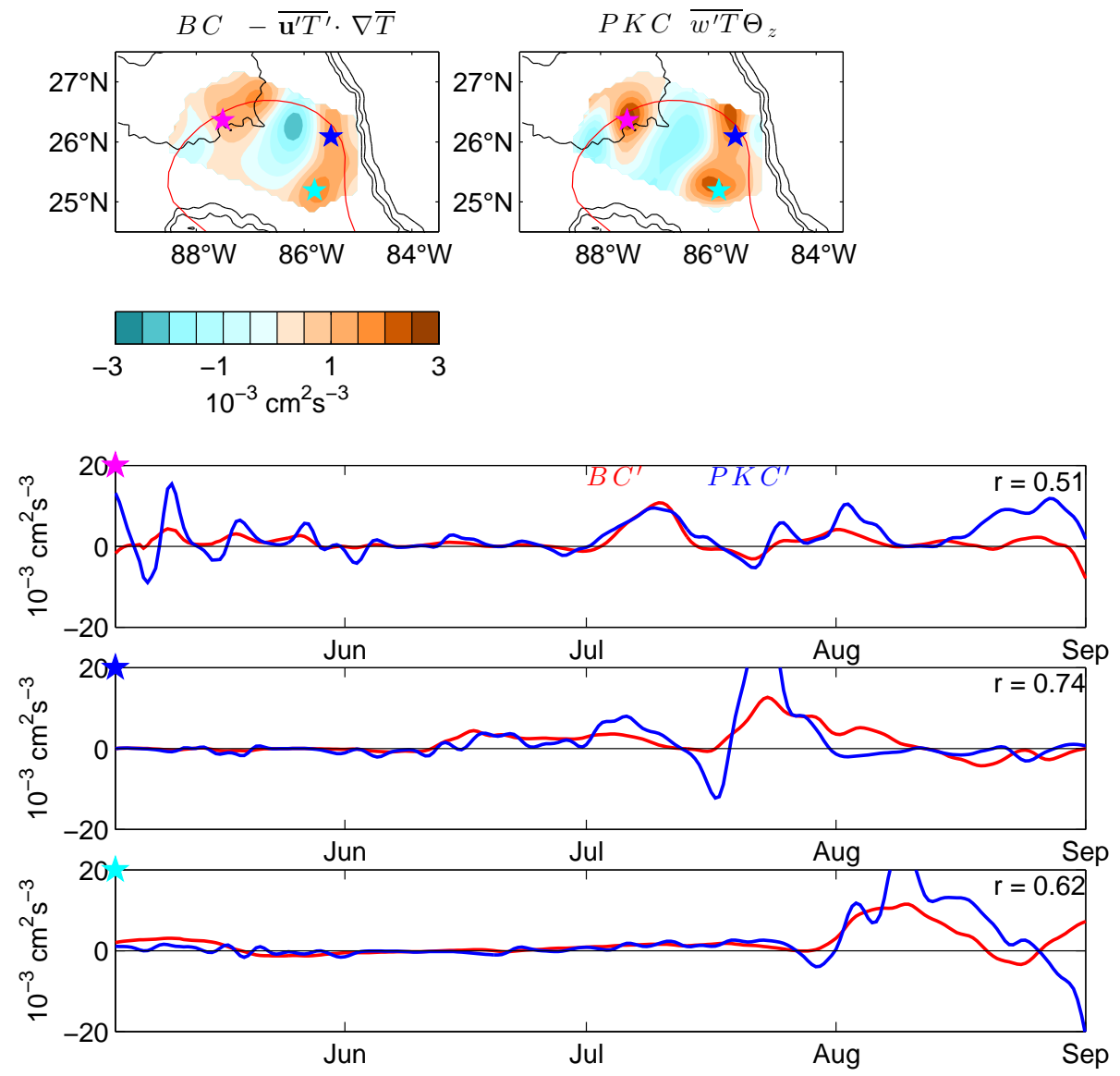

Figure 17: Top panels: BC (left) and PKC (right) at $400 \mathrm{~m}$ depth determined for the Ekman event (contour interval after multiplication by $g \alpha / \Theta_{z}=428 \mathrm{~cm}^{2} \mathrm{~s}^{-2 \circ} \mathrm{C}^{-2}$ is $0.5 \times 10^{-3} \mathrm{~cm}^{2} \mathrm{~s}^{-3}$; in colorbar blues hues are negative and orange hues are positive). The red line denotes the mean position of the $17 \mathrm{~cm}$ altimeter-mapped SSH contour. Bathymetry (thick black lines) contoured every $1000 \mathrm{~m}$ depth. Bottom three panels: time series of $\mathrm{BC}^{\prime}$ (red) and $\mathrm{PKC}^{\prime}$ (blue) at locations indicated by colored stars in the mapped energetic terms (top panels) and denoted on the top left corner of each time series plot. 
Franklin Feb.15,2010 through Sep.14,2010 400 m depth
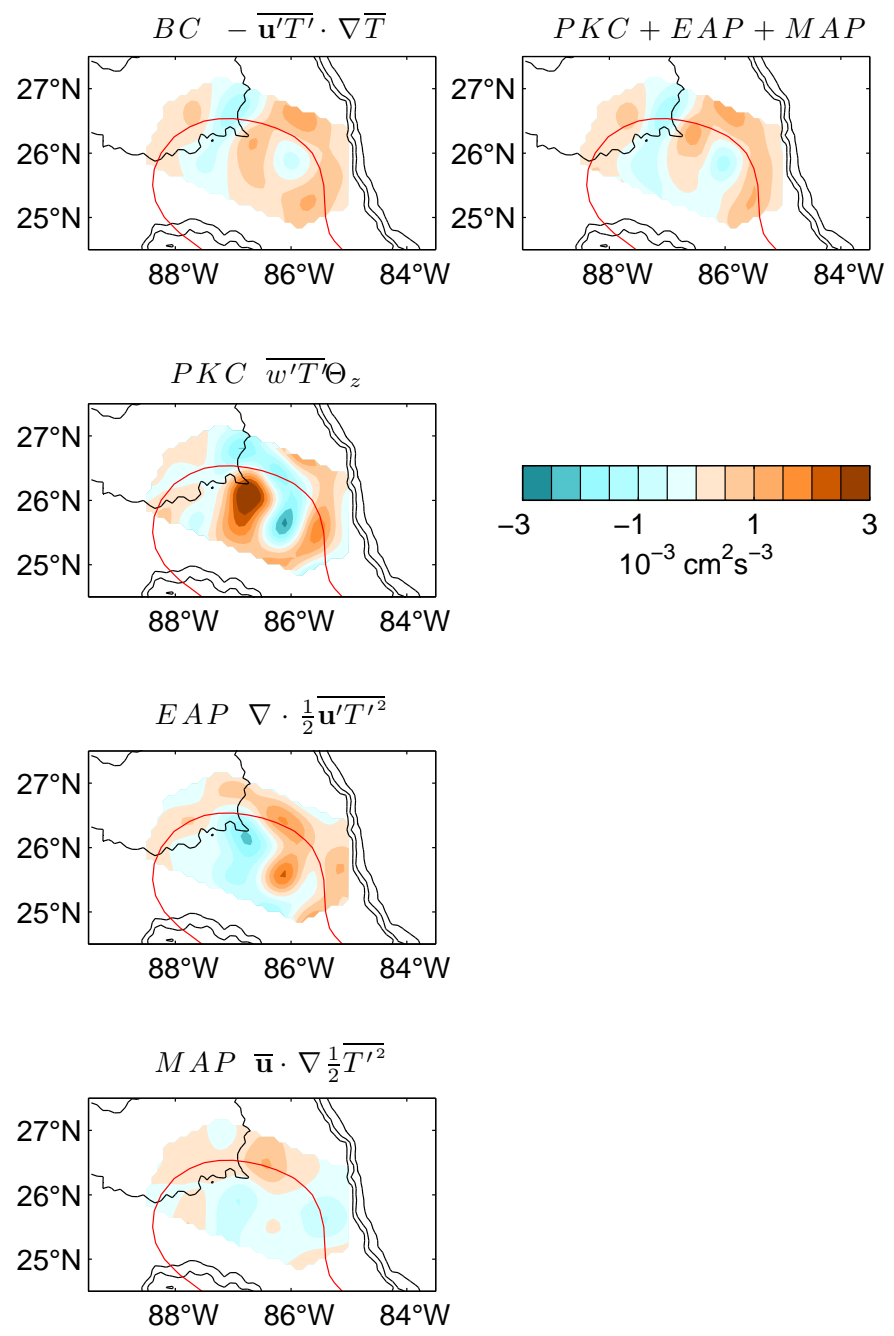

Figure 18: Four terms in the steady eddy potential energy budget (Eqn 15) determined for the Franklin event February 15 through September 14, 2010 at $400 \mathrm{~m}$ depth (contour interval after multiplication by $g \alpha / \Theta_{z}=428 \mathrm{~cm}^{2} \mathrm{~s}^{-2}{ }^{\circ} \mathrm{C}^{-2}$ is $0.5 \times 10^{-3} \mathrm{~cm}^{2} \mathrm{~s}^{-3}$; in colorbar blues hues are negative and orange hues are positive). The horizontal downgradient eddy heat flux (BC) is balanced by the mean advection of eddy potential energy (MAP), eddy advection of eddy potential energy (EAP) and the vertical downgradient heat flux (PKC). Right panel shows the sum of the PKC, EAP and MAP terms. The red line denotes the mean position of the $17 \mathrm{~cm}$ altimeter-mapped SSH contour. Bathymetry (thick black lines) contoured every $1000 \mathrm{~m}$ depth. 50 
Franklin Feb.15,2010 through Sep.14,2010 400 m depth
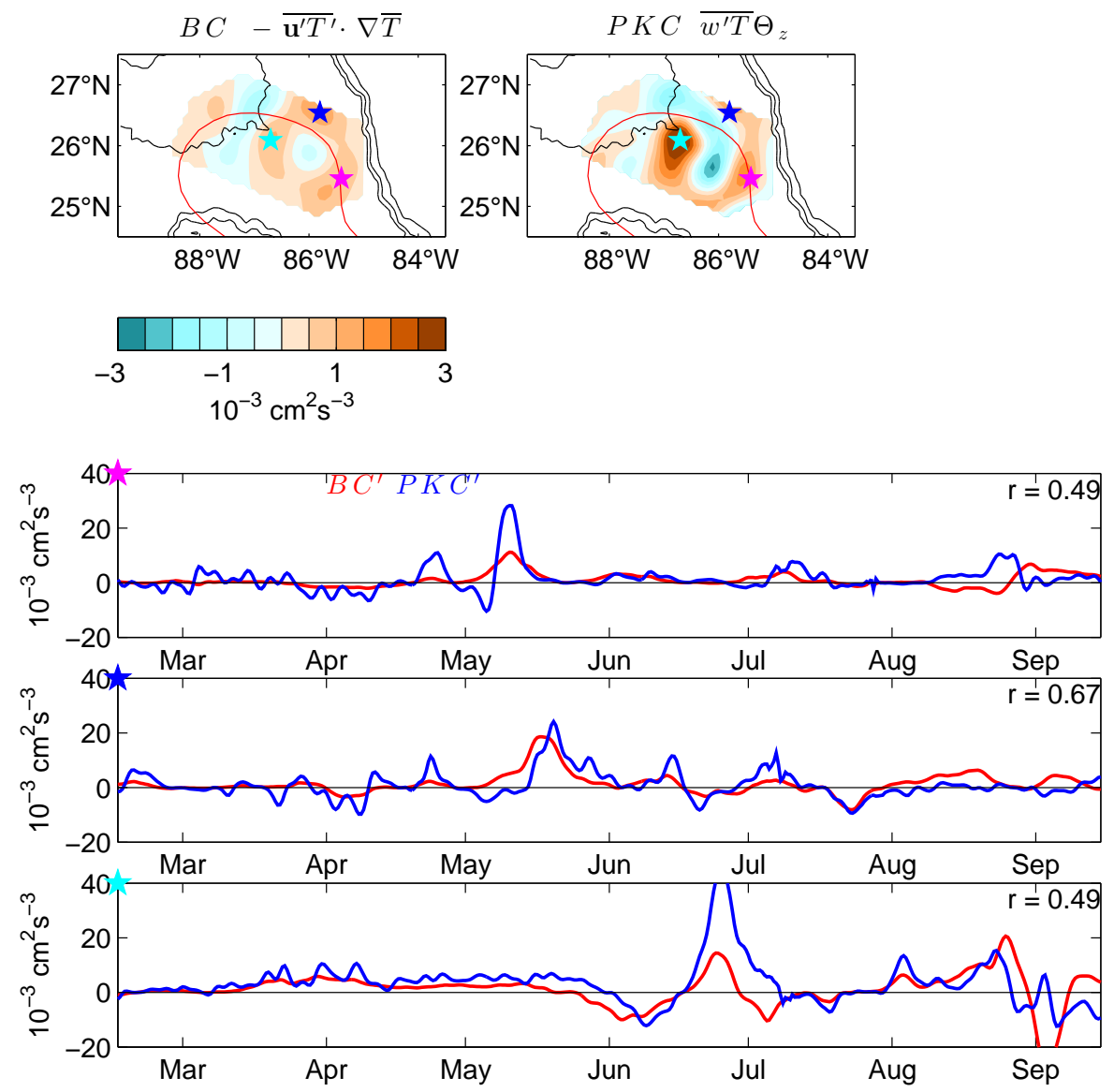

Figure 19: Top panels: BC (left) and PKC (right) at $400 \mathrm{~m}$ depth determined for the Franklin event (contour interval after multiplication by $g \alpha / \Theta_{z}=428 \mathrm{~cm}^{2} \mathrm{~s}^{-2 \circ} \mathrm{C}^{-2}$ is $0.5 \times 10^{-3} \mathrm{~cm}^{2} \mathrm{~s}^{-3}$; in colorbar blues hues are negative and orange hues are positive). The red line denotes the mean position of the $17 \mathrm{~cm}$ altimeter-mapped SSH contour. Bathymetry (thick black lines) contoured every $1000 \mathrm{~m}$ depth. Bottom three panels: time series of $\mathrm{BC}^{\prime}$ (red) and $\mathrm{PKC}^{\prime}$ (blue) at locations indicated by colored stars in the mapped energetic terms (top panels) and denoted on the top left corner of each time series plot. 
Hadal Mar.01,2011 through Sep.14,2011 $400 \mathrm{~m}$ depth
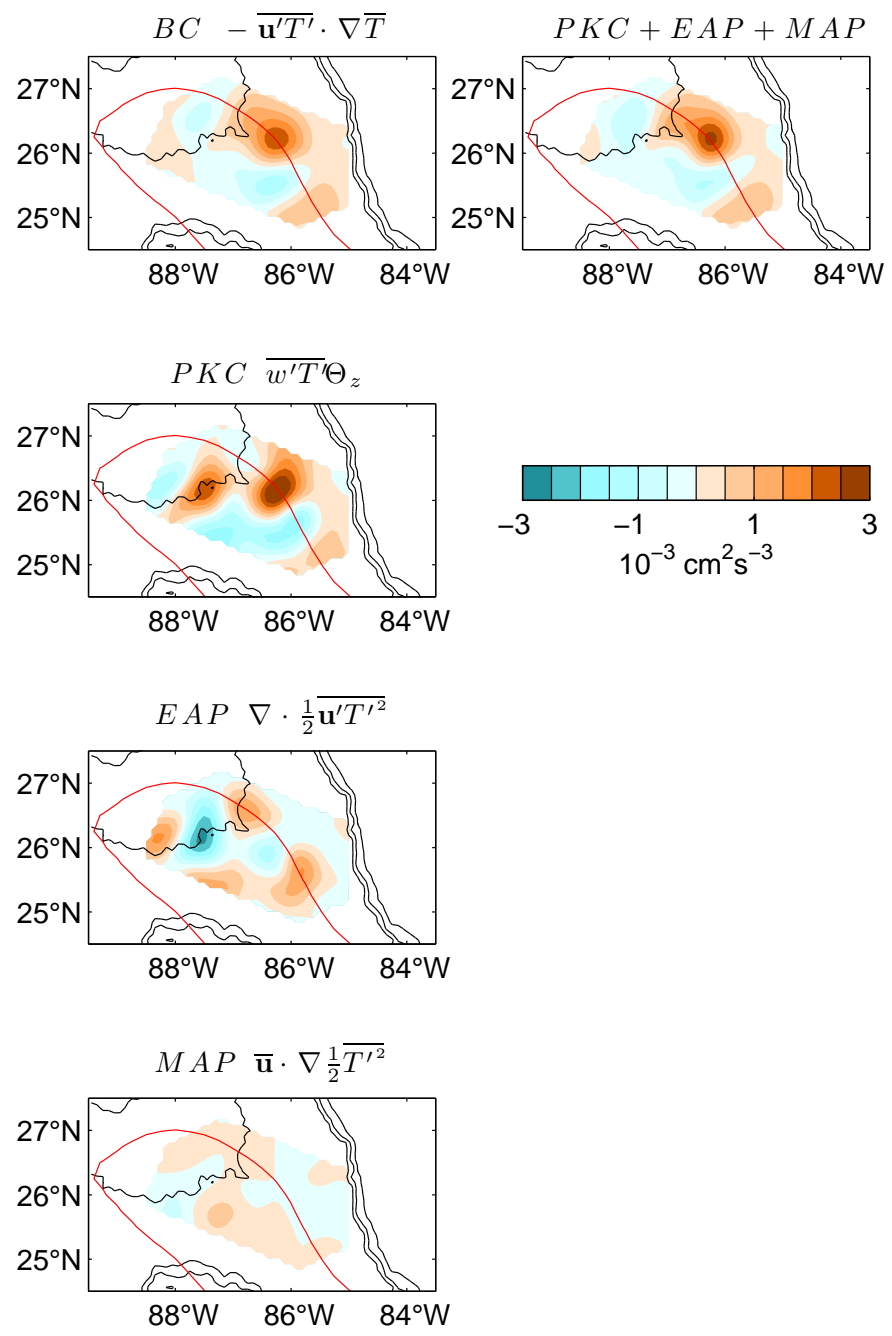

Figure 20: Four terms in the steady eddy potential energy budget (Eqn15) determined for the Hadal event March 1 through September 14, 2011, at $400 \mathrm{~m}$ depth (contour interval after multiplication by $g \alpha / \Theta_{z}=428 \mathrm{~cm}^{2} \mathrm{~s}^{-2 \circ} \mathrm{C}^{-2}$ is $0.5 \times 10^{-3} \mathrm{~cm}^{2} \mathrm{~s}^{-3}$; in colorbar indicates blues hues are negative and orange hues are positive). The horizontal downgradient eddy heat flux (BC) is balanced by the mean advection of eddy potential energy (MAP), eddy advection of eddy potential energy (EAP) and the vertical downgradient heat flux (PKC). Right panel shows the sum of the PKC, EAP and MAP terms. The red line denotes the mean position of the $17 \mathrm{~cm}$ altimeter-mapped SSH contour. Bathymetry (thick black lines) contoured every $1000 \mathrm{~m}$ depth. 52 
Hadal Mar.01,2011 through Sep.14,2011 $400 \mathrm{~m}$ depth
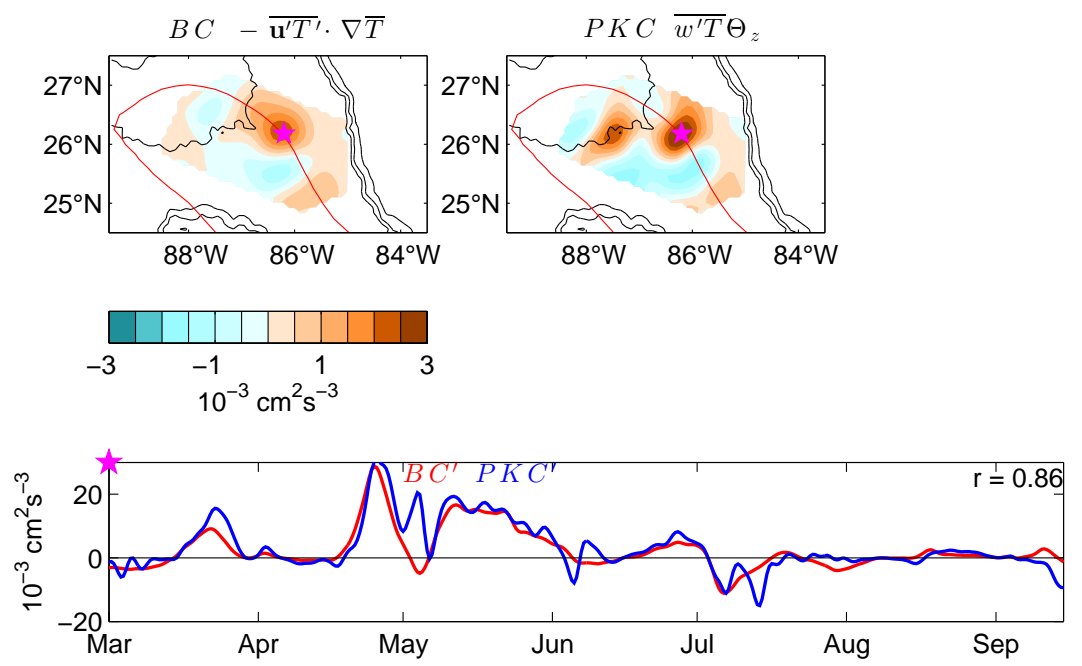

Figure 21: Top panels: BC (left) and PKC (right) at $400 \mathrm{~m}$ depth determined for the Hadal event (contour interval after multiplication by $g \alpha / \Theta_{z}=428 \mathrm{~cm}^{2} \mathrm{~s}^{-2 \circ} \mathrm{C}^{-2}$ is $0.5 \times 10^{-3} \mathrm{~cm}^{2} \mathrm{~s}^{-3}$; in colorbar blues hues are negative and orange hues are positive). The red line denotes the mean position of the $17 \mathrm{~cm}$ altimeter-mapped SSH contour. Bathymetry (thick black lines) contoured every $1000 \mathrm{~m}$ depth. Bottom three panels: time series of $\mathrm{BC}^{\prime}$ (red) and $\mathrm{PKC}^{\prime}$ (blue) at locations indicated by colored stars in the mapped energetic terms (top panels) and denoted on the top left corner of each time series plot. 